\title{
The Poor, the Rich and the Enforcer: Institutional Choice and Growth
}

\author{
ERwan Quintin, Thorsten Koeppl \\ AND \\ Cyril Monnet \\ Research Department \\ Working Paper 0801
}

Federal Reserve Bank of Dallas 


\title{
The Poor, the Rich and the Enforcer: Institutional Choice and Growth
}

\author{
Thorsten Koeppl \\ Cyril Monnet \\ Queen's University \\ Federal Reserve Bank of Philadelphia \\ Erwan Quintin* \\ Federal Reserve Bank of Dallas
}

December 31, 2007

\begin{abstract}
We study economies where improving the quality of institutions - modeled as improving contract enforcement - requires resources, but enables trade that raises output by reducing the dispersion of marginal products of capital. We find that in this type of environment it is optimal to combine institutional building with endowment redistribution, and that more ex-ante dispersion in marginal products increases the incentives to invest in enforcement. In addition, we show that institutional investments lead over time to a progressive reduction in inequality. Finally, the framework we describe enables us to formalize the hypothesis formulated by Engerman and Sokoloff (2002) that the initial concentration of human and physical capital can explain the divergence of different countries' institutional history.
\end{abstract}

Keywords: Enforcement as a Choice; Institutions; Inequality; Human and Physical Capital. JEL Classification: D31; D52; O11; O43.

\footnotetext{
*E-mail: thor@econ.queensu.ca, cyril.monnet@phil.frb.org, erwan.quintin@dal.frb.org. We would like to thank Per Krusell, Huw Lloyd-Ellis, Elias Papaioanou, B Ravikumar, Richard Rogerson and seminar participants at the Federal Reserve Bank of Richmond for many helpful comments. The views expressed in this paper are not necessarily those of the Federal Reserve Bank of Philadelphia, Federal Reserve Bank of Dallas or the Federal Reserve System.
} 


\section{Introduction}

A well-functioning legal and institutional environment is pivotal to achieve an efficient allocation of resources. As Rajan and Zingales (2003) put it, proper institutions allow economies to "[unleash] the power of financial markets to create wealth and spread opportunity." Somewhat surprisingly then, ineffective institutions appear to be remarkably persistent in many countries. What causes some countries to develop well-functioning institutions, while others, even at similar stages of economic development, don't? ${ }^{1}$ A large literature emphasizes political forces as a determinant of institutional quality. ${ }^{2}$ The standard argument is summarized by Rajan and Zingales (2003), who write that "[t]he economically powerful are concerned about the institutions underpinning free markets because they treat people equally, making power redundant." In this paper, we adopt a completely different approach and consider a model where institutional choice is based on efficiency considerations alone.

Our model borrows the key features of standard models in the vast literature on the interplay between inequality and growth. ${ }^{3}$ Specifically we study economies populated by agents endowed with a production technology characterized by decreasing returns to scale, and with different amounts of productive resources. These features imply that there are potential gains from trading capital. We assume however that trade is constrained by the fact that enforcement is limited in the sense that agents can default on any promise to deliver goods after production is complete.

We then introduce a technology that imposes a penalty on people who renege on their obligations. The intensity of punishment rises with the quantity of capital invested in this technology. As enforcement improves, agents can choose from a wider set of contracts, and the dispersion of marginal products is reduced. However, larger investments in enforcement leave less capital available for production. ${ }^{4}$

To study the resulting trade-off, we first consider a planner that allocates capital to maximize aggregate output subject to enforcement constraints. Some agents must be willing to give up some of their endowment to finance enforcement but, in return, they receive transfers

\footnotetext{
${ }^{1}$ Engerman and Sokoloff (2002) point out for instance that while economies in the Western Hemisphere were at fairly similar levels of development as recently as two centuries ago, the United States and Canada were much quicker to develop institutions conducive to trade than the rest of the continent.

${ }^{2}$ See for example Persson and Tabellini (1994), Acemoglu, et al. (2005), Acemoglu and Johnson (2005), Acemoglu and Robinson (2007) among many others.

${ }^{3}$ See Benabou (1996) and Aghion et al. (1999) for reviews of this literature.

${ }^{4}$ This part of our set-up closely follows Koeppl (2007) who studies enforcement choices in the context of intertemporal risk sharing.
} 
after production has occurred. The optimal allocation reduces the dispersion of marginal products by optimally combining endowment redistribution with investments in the enforcement technology. We show that the resulting income distribution is a left-censored version of the distribution that would prevail under autarky.

We implement the solution to the social planner problem as a competitive equilibrium of an economy with endogenous borrowing constraints. The investment in enforcement is now financed by fees that grant agents access to capital markets. Endowment-rich agents provide the capital necessary for investing in enforcement, and effectively subsidize endowment-poor agents. Competitive trade then achieves an efficient allocation of capital given the optimal enforcement level, with the effects of the subsidy and benefits from trade being concentrated at the bottom of the initial endowment redistribution. These benefits are larger the more unequally marginal products are initially distributed. ${ }^{5}$

We then describe the dynamics of enforcement assuming simple intergenerational linkages, and analyze the interplay between institutional investments and the evolution of endowment and income inequality. Over time, endowment and income inequality are reduced, as endowment-poor agents gain the most from investing in enforcement. As inequality diminishes over time, so does the investment in enforcement.

Our results have important implications for the growing literature on the effects of inequality on economic growth. That literature has produced a variety of models ${ }^{6}$ that predict that when markets are incomplete, redistributing resources can foster growth. We find that once one treats market incompleteness as endogenous, the optimal policy in these environment should comprise investments in institutions that improve the functioning of markets. In fact, while the optimal solution also calls for some redistribution of endowments in our model, institutional investments make that redistribution possible in the first place by allowing agents who contribute to it to benefit from trade.

Endogenizing market incompleteness also reveals that more ex-ante dispersion in marginal products should lead to more institutional investments. At first glance, this prediction appears

\footnotetext{
${ }^{5}$ In light of our implementation result, modeling enforcement as a technology can be interpreted in two complementary ways. Enforcement allows one to set up a market environment for decentralized exchange of capital. This includes the institutions necessary to enforce property rights and the obligations that arise from trade. Alternatively, the technology can be seen as a redistributive tax system, where capital is reallocated before production and where taxes redistribute income after production. In both interpretations, investment costs are incurred ex-ante to set up the necessary institutions. This includes not only setting up and maintaining a legal framework, but also building the institutions necessary to enforce it.

${ }^{6}$ For a review, see Benabou (1997).
} 
to contradict the hypothesis formulated by Engerman and Sokoloff (2002) that, at least in the western hemisphere, nations with more equal distributions of human and physical capital were first to develop institutions conducive to credit and trade. We argue however that our model, far from contradicting this hypothesis, provides additional support for it. Engerman and Sokoloff (2002) describe XIXth century Latin America as an area where both human and physical capital were highly concentrated. North-America, however, had less inequality in both capital, and developed better market-supporting institutions. When human and physical capital are complementary in production, a high concentration of productive resources may result in little dispersion in marginal products. We show that a sufficiently high positive correlation between human and physical capital endowment leads to small differences in marginal products across people, hence to little incentives for investing in institutions conducive to trade. ${ }^{7}$ What matters are the gains from building institutions rather than inequality per se. $^{8}$

This is particularly relevant for the ongoing debate on the relative importance of human capital and institutional quality for economic development. ${ }^{9}$ Our findings suggest that the two are intimately related and cannot be separated. Investment in human capital raises the returns to investment in institutions. Conversely, better institutions enable nations to direct physical resources to their most productive uses, which raises returns to human capital development. Under those circumstances, the question of whether institution quality or human capital is the key to development success may be immaterial, as it is the dynamic interaction between the two that matters.

More generally, our paper suggests that in order to understand the relationship between institutions, inequality and growth, one must not only look at the incentives for building institutions, but also at where the gains from such institutions arise and how they can be redistributed throughout the economy. We thus offer a new approach that is free from assumptions on how political processes interact with economic efficiency, thus providing a compelling benchmark that - if necessary - can be enriched by such considerations.

\footnotetext{
${ }^{7}$ See also Bernhardt and Lloyd-Ellis (2000) that point to general differences in marginal products rather than inequality per se as the key to understand lack in growth performance.

${ }^{8}$ This exposes a complex relationship between measures of inequality and economic performance which could account for why empirical studies struggle to establish robust results for this relationship. See for example Benabou (1996) or, more recently, Banerjee and Duflo (2003).

${ }^{9}$ See for example Glaeser et al. (2004) or Galor and Moav (2006).
} 


\section{The Environment}

We study an economy where short-lived generations decide how much to invest in an enforcement technology. Time is discrete and denoted by $t \in\{0,1, \ldots\}$. The economy is populated by a continuum of infinitely lived families indexed by $i \in[0,1]$. At time $t \geq 0$, a single member of each family $i \in[0,1]$ is alive. This agent is endowed with a quantity $a_{i}^{t} \geq 0$ of capital. We will assume throughout this paper that the distribution of endowments is non-degenerate in all periods, and that the endowment function is sufficiently smooth on $[0,1]$ to allow us to invoke the maximum principle where needed.

Each period, all agents are endowed with a technology that transforms input $k \geq 0$ of capital into quantity $k^{\alpha}$ of the consumption good where $\alpha \in(0,1)$. We adopt this CobbDouglas specification of the production schedule for concreteness. Assuming a strictly concave and increasing production function suffices, however, to derive our results. All agents seek to maximize their end-of-period income.

Since the production function is strictly concave and the endowment distribution is nondegenerate, agents have clear incentives to trade capital in this context. Specifically, agents with low capital endowments would like to borrow some capital from other agents in exchange for end-of-period payments. We assume, however, that enforcement is limited. Agents can default on any transfer they owe at the end of the period, ${ }^{10}$ in which case they incur a a real $\operatorname{cost} \eta_{t}>0$ denominated in consumption-equivalent units. $^{11}$

We begin below by briefly considering the case where the punishment level is exogenous. Clearly however, raising the level of punishment (hence the degree to which contracts can be enforced) is costly, and our main objective in this paper is to study the resulting trade-off. We will endogenize the enforcement choice by assuming that establishing enforcement level $\eta \geq 0$ in any given period induces a capital cost $g(\eta) \geq 0$ that must be borne before production begins. We will assume that $g$ is strictly convex, strictly increasing and twice differentiable on $(0,+\infty)$, and that $g(0)=0$. We allow for the possibility that $\lim _{\eta \backslash 0} g(\eta)>0$ to make room for fixed costs. Finally, we assume for simplicity that investments in enforcement fully depreciate across periods.

\footnotetext{
${ }^{10}$ For simplicity, we will assume that agents are not liable for the actions of other members of their lineage.

${ }^{11}$ This formulation follows Sappington (1983) and Banerjee and Newman (1993) among others. One could also assume that default costs rise with capital (or, equivalently, output) according to a schedule $D(\eta, k)$ for all $\eta, k \geq 0$ as long as $D$ is jointly concave in both of its arguments.
} 


\section{Enforcement and the Efficient Allocation of Capital}

In this section, we study the problem solved by a given generation. Since each generation solves a static problem, we omit for now the dependence of variables on time. The next section will deal with the possibility of dynamic linkages across generations.

\subsection{Optimal Capital Allocation for a Given Enforcement Level}

We consider first the situation where $\eta$ is exogenous and requires no cost, and where agents behave competitively. This will serves as a benchmark for the rest of the analysis.

Agents can trade capital at the beginning of the period at a gross interest rate $R>0$. They behave competitively in that they take this rate as given. In equilibrium, this rate is such that the market for capital clears. ${ }^{12}$ Agent $i \in[0,1]$ solves

$$
\max _{k_{i}} k_{i}^{\alpha}+\left(a_{i}-k_{i}\right) R
$$

subject to

$$
\left(k_{i}-a_{i}\right) R \leq \eta
$$

The constraint states that agents can only write contracts such that making good on end-ofperiod obligations is individually rational.

The solution to this problem is easy to describe. Given $R>0$, there exists an asset threshold past which agents are unconstrained. Below that threshold, capital use rises onefor-one with the agent's endowment. Furthermore, it is clear that when $\eta$ is sufficiently high, no agent is constrained and markets are effectively complete. On the other hand, when $\eta=0$, trade is impossible and all production must be self-financed. The following result says that, more generally, a higher enforcement level leads higher interest rates and higher aggregate output.

Proposition 3.1. Given $\eta$, a unique competitive equilibrium exists. Furthermore, aggregate output and the equilibrium interest rate $R$ rise with enforcement level $\eta$.

Proof. The aggregate supply of capital is $\int a_{i} d i$, independently of both $\eta$ and of $R$. Given $\eta$, increases in $R$ lower capital use because this makes capital more costly and makes borrowing

\footnotetext{
${ }^{12}$ The model then becomes a simplified version of the set up studied by much of the literature on inequality and growth. See for example Aghion (1998) and Benabou (1996).
} 
constraints tighter. Therefore, the demand schedule is monotonically declining in $R$, and equilibria are unique.

For the second part of the proposition, fix $\eta$ and let $R(\eta)$ be the corresponding equilibrium price of capital. One easily shows that the equilibrium allocation of capital given $\eta$ solves

$$
\max _{\left\{k_{i} \mid i \in[0,1]\right\}} \int k_{i}^{\alpha} d i
$$

subject to

$$
\begin{aligned}
\int k_{i} d i & \leq \int a_{i} d i \\
\left(k_{i}-a_{i}\right) R(\eta) & \leq \eta \text { for almost all } i
\end{aligned}
$$

Therefore, the desired result follows provided $\frac{\eta}{R(\eta)}$ rises with $\eta$.

Assume to the contrary that $\eta$ rises to $\eta^{\prime}$, but that $\frac{\eta}{R(\eta)}>\frac{\eta^{\prime}}{R\left(\eta^{\prime}\right)}$. Then all agents are more borrowing constrained and capital becomes more expensive. Hence, capital demand falls for all agents. But that contradicts the fact that both $R(\eta)$ and $R\left(\eta^{\prime}\right)$ are equilibrium rates, since aggregate capital supply is the same in both cases.

Figure 3.1 illustrates this result. Given enforcement level $\eta$ and the implied equilibrium interest rate $R(\eta)$, there is a unique optimal scale $k(\eta)$ of production. Agents with endowment past asset threshold $a(\eta) \equiv k(\eta)-\frac{\eta}{R(\eta)}$ are unconstrained, while other agents operate with a capital stock equal to $k_{i}=a_{i}+\frac{\eta}{R(\eta)}$. Equilibrium capital input, therefore, rises one-for-one with initial endowment until agents become unconstrained.

When enforcement increases from $\eta$ to $\eta^{\prime}$, borrowing constraints are relaxed and the demand for capital shifts up at all rental rates. As the total supply of capital is fixed, it must be the case that the equilibrium interest rate $R$ increases. A higher equilibrium interest rate causes the optimal scale of production for unconstrained agents to fall. Because (once again) the total supply of capital is fixed, the two schedules must cross and it must therefore be the case that $\eta^{\prime} / R\left(\eta^{\prime}\right)>\eta / R(\eta)$. As a result, the dispersion in marginal products declines and output, correspondingly, rises.

The relationship between the dispersion in marginal products and the enforcement level $\eta$ is the centerpiece of our analysis. Improvements in enforcement raise output much in the way a policy of redistributing initial capital would do in this framework: both make marginal products more homogeneous. Moreover, when enforcement is limited at a particular level, as 


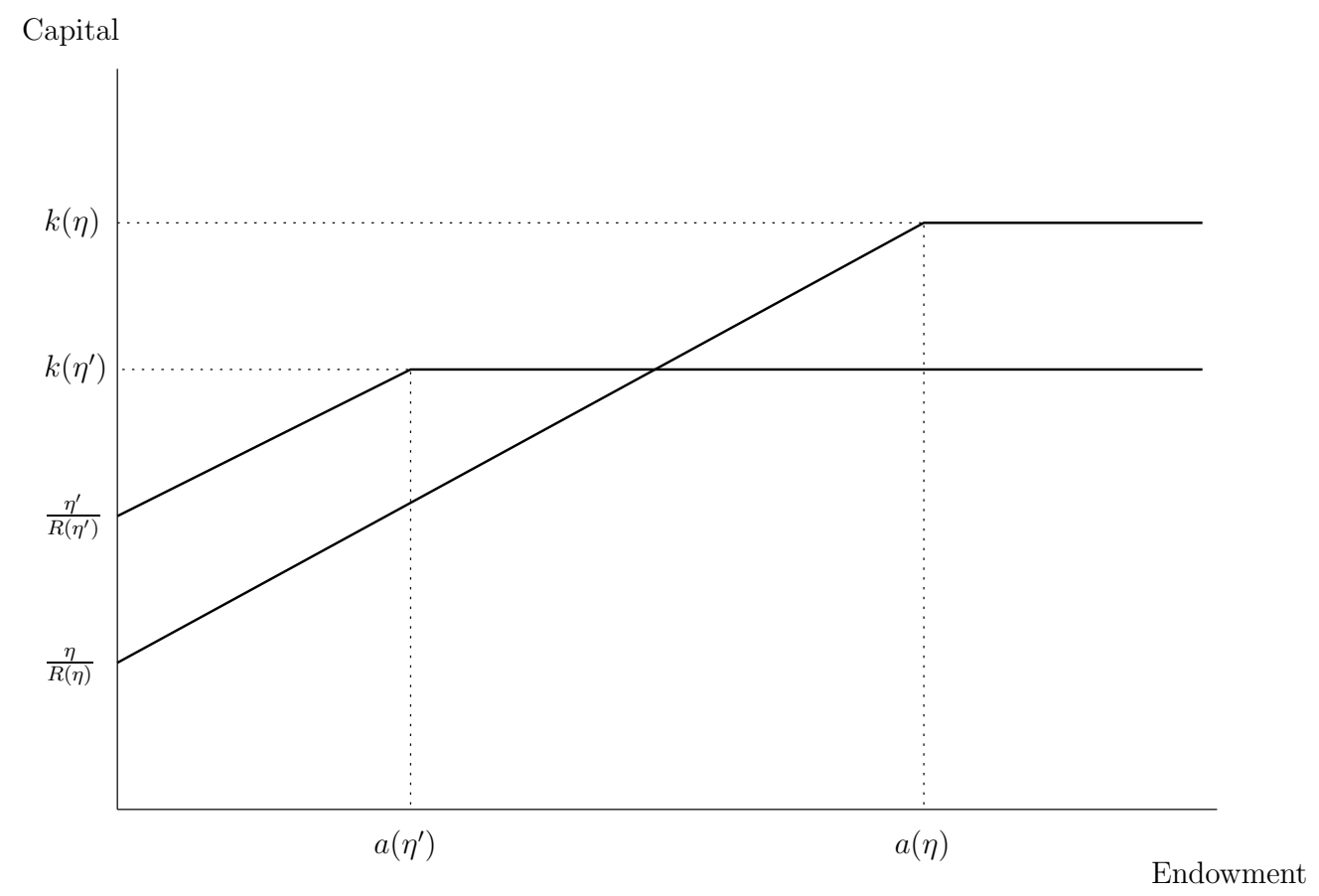

Figure 1: Optimal capital allocation ( $\eta$ exogenous; no cost)

inequality in wealth - i.e., the initial capital endowment - increases, borrowing constraints become more binding. In equilibrium, there is more dispersion in marginal products across agents and, therefore, less output.

\subsection{The Optimal Level of Enforcement}

The foregoing analysis suggests that economies where endowments are unevenly distributed have an incentive to establish institutions that make possible a reduction in the dispersion of marginal products. In practice, however, these institutions are costly to provide. A trade-off thus arises between using resources for costly institutions or producing output.

We consider first a planner whose objective is to maximize aggregate output. This focuses the analysis on pure efficiency considerations since such a planner has no direct interest in reducing inequality. In addition, we prove in the appendix that this entails little loss of generality. Assuming that the planner maximizes a strictly concave welfare functional over agent's end-of-period income does not change the nature of the optimal allocation. The inclusion of ex-ante participation and ex-post enforcement constraints implies that there is no room for redistributing income at the end of the period once efficiency considerations have 
been taken into account.

Given a distribution of endowment, the planner proposes a capital allocation $k=\left\{k_{i} \geq\right.$ $0 \mid i \in[0,1]\}$, a schedule of post-production transfers $t=\left\{t_{i} \in \mathbb{R} \mid i \in[0,1]\right\}$, and a degree $\eta \geq 0$ of enforcement. The planner's proposal is restricted in two ways. First, agents can choose to stay in autarky rather than participate in the proposed arrangement. Second, agents can decide to default on the post-production transfer stipulated by the planner in which case they incur punishment $\eta$.

Formally, the planner solves

$$
\max _{(k, t, \eta)} \int k_{i}^{\alpha} d i
$$

subject to

$$
\begin{aligned}
\int k_{i} d i+g(\eta) & =\int a_{i} d i \\
k_{i}^{\alpha}-t_{i} & \geq a_{i}^{\alpha} \text { for almost all } i \\
t_{i} & \leq \eta \text { for almost all } i \\
\int t_{i} d i & \geq 0 .
\end{aligned}
$$

The first constraint is a resource feasibility constraint. The second set of constraints stipulates that agents have to be willing to participate in the proposed arrangement given that they can always opt for autarky. The third set of conditions expresses the fact that transfer enforcement is limited. The final constraint expresses the fact that the planner cannot invent resources at the end of the period. Setting transfers to zero implies that maximizing output (or income before transfers) is equivalent to maximizing average consumption or total income after transfers.

Our first result states that because raising the enforcement level is costly, the planner never chooses to eliminate all inequality in marginal products.

Proposition 3.2. The optimal allocation with endogenous enforcement is such that $k_{i}$ is not almost everywhere equal.

Proof. Denote the multipliers associated with the constraints $(3.1)-(3.4)$ by $\theta,\left\{\lambda_{i} \mid i \in[0,1]\right\}$, $\left\{\mu_{i} \mid i \in[0,1]\right\}$ and $\tau$, respectively. If the planner chooses not to invest in enforcement $(\eta=0)$, then $k_{i}=a_{i}$ almost everywhere and the result holds trivially. Assume then that $\eta>0$. 
Necessary conditions for an interior solution to the planner's problem are given by ${ }^{13}$

$$
\begin{aligned}
\theta g^{\prime}(\eta)-\int \mu_{i} d i & =0 \\
\alpha k_{i}^{\alpha-1}\left(1+\lambda_{i}\right)-\theta & =0 \text { for almost all } i \\
-\lambda_{i}-\mu_{i}+\tau & =0 \text { for almost all } i .
\end{aligned}
$$

Also note that, together with the usual slackness conditions, these conditions are sufficient.

Assume now by way of contradiction, that $k_{i}$ is constant a.e. Then, $\lambda_{i}$ is constant a.e. as well by condition (3.6), as is $\mu_{i}$ by condition (3.7). But since $\eta>0$, resource feasibility requires that $a_{i}>k_{i}$ for a non-negligible set of $i$. This implies that $t_{i}<\eta$ and $\mu_{i}=0$ for that set. Hence, we need $\mu_{i}=0$ for almost all $i$, which cannot be the case by condition (3.5), given that $\eta>0$ and that, by (3.6), $\theta>0$.

The intuition for this result is straightforward. When capital use is equated across agents, marginal products are equated as well. It follows that small deviations from such an allocation have a negligible impact on output. On the other hand, reducing enforcement has a first-order effect on the resources available for production.

We now turn to establishing that a unique solution to the planner's problem exists and to characterizing this optimal allocation.

Proposition 3.3. Generically, a unique solution to the social planner's problem exists. Furthermore, the optimal allocation is characterized by two endowment thresholds $0 \leq \underline{a} \leq \bar{a}$ and two bounds $0 \leq \underline{k} \leq \bar{k}$ on capital use that determine the optimal capital allocation for almost all $i$ according to

$$
k_{i}= \begin{cases}\underline{k} & \text { if } a_{i} \leq \underline{a} \\ \left(a_{i}^{\alpha}+\eta\right)^{\frac{1}{\alpha}} & \text { if } a_{i} \in[\underline{a}, \bar{a}] \\ \bar{k} & \text { if } a_{i} \geq \bar{a} .\end{cases}
$$

End-of-period income is given by

$$
k_{i}^{\alpha}-t_{i}= \begin{cases}\underline{a}^{\alpha} & \text { if } a_{i} \leq \underline{a} \\ a_{i}^{\alpha} & \text { if } a_{i} \geq \underline{a} .\end{cases}
$$

\footnotetext{
${ }^{13}$ See Cesari (1983). Our set of constraints satisfies a standard constraint qualification.
} 
Proof. In order to apply Filippov's existence theorem, ${ }^{14}$ we need to restrict transfers and capital choices to a compact set. To do so, one can impose arbitrary bounds on both objects that are large enough not to bind at any solution. This ensures existence.

To establish generic uniqueness, note that given the fixed cost associated with implementing the enforcement technology, we need to compare the value of the problem when $\eta=0-$ i.e., the value of the problem at autarky - and the value of the problem when the planner chooses to bear the fixed enforcement cost $\lim _{\eta \searrow_{0}} g(\eta)$.

This second problem corresponds to solving the problem assuming that $g(0)=\lim _{\eta \backslash 0} g(\eta)$. We will argue that the solution under that assumption is unique, so that the only case in which multiple solutions exist is when that solution happens to give exactly the same value as autarky. Generically therefore, there is at most one solution.

Under the assumption that $g(0)=\lim _{\eta \backslash 0} g(\eta)$, the planner's choice set is convex in $(\eta, k, t)$. Since the planner's objective function is strictly concave in $k$, there is at most one optimal capital allocation in that case. The resource constraint then implies that $\eta$ must be unique as well. The transfer scheme is also unique because, as we argue below, either the participation or the enforcement constraint must bind for all agents. If the enforcement constraint binds, we have $t_{i}=\eta$. If the participation constraint of the agent is binding, transfers are given by $t_{i}=k_{i}^{\alpha}-a_{i}^{\alpha}$.

We now turn to describing the optimal solution. As $\eta=0$ implies autarky in which case our characterization holds trivially, we assume that the optimal solution has $\eta>0$. Conditions (3.5)-(3.7) together with the associated slackness conditions describe the optimal solution. We first establish that for almost all agents, either the participation or the enforcement constraint holds with equality. Assume to the contrary that for some non-negligible set of agents this is not the case. Then, by condition (3.7), this is true for all agents. But this contradicts condition (3.5) whenever $\eta>0$ since $\theta>0$ by (3.6).

Consider next the set of agents with non-binding enforcement constraints $\left(\mu_{i}=0\right)$. For these agents, $\lambda_{i}=\tau$ which implies that $k_{i}=\bar{k} \equiv\left(\frac{\alpha(1+\tau)}{\theta}\right)^{\frac{1}{1-\alpha}}$. On the other hand, agents whose participation constraint is slack employ capital $\underline{k} \equiv\left(\frac{\alpha}{\theta}\right)^{\frac{1}{1-\alpha}}<\bar{k}$. Finally, agents for

\footnotetext{
${ }^{14}$ See section 4.8 in Cesari (1983) for a discussion of Mayer problems such as ours with integral (isoperimetric) constraints.
} 


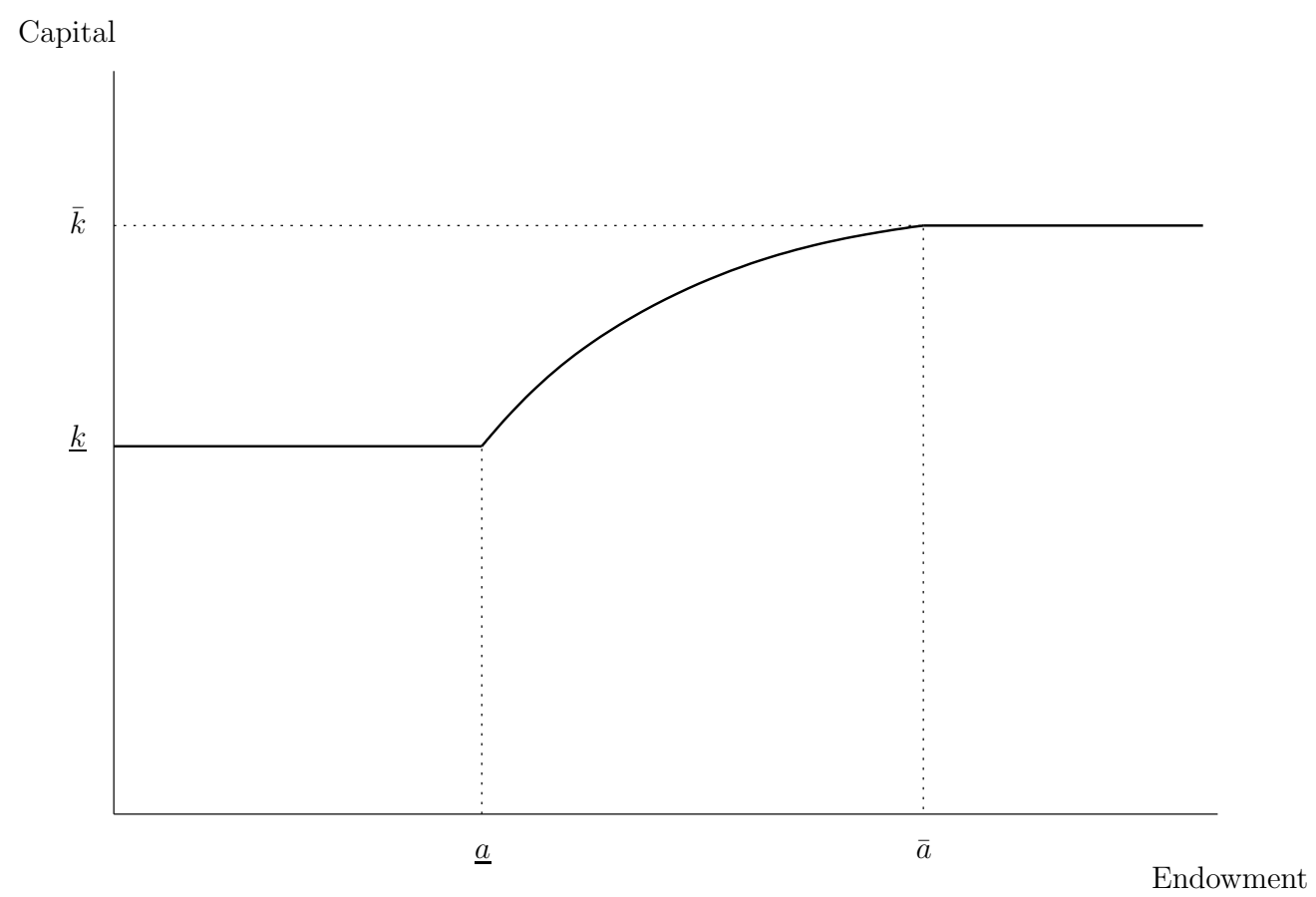

Figure 2: Optimal capital allocation ( $\eta$ endogenous; convex cost)

which both constraints bind employ

$$
k_{i}=\left(\frac{\alpha\left(1+\tau-\mu_{i}\right)}{\theta}\right)^{\frac{1}{1-\alpha}}=\left(a_{i}^{\alpha}+\eta\right)^{\frac{1}{\alpha}} \in[\underline{k}, \bar{k}]
$$

There only remains to be shown that these three groups of agents are separated by certain asset thresholds. If agent $i \in[0,1]$ is in the group with non-binding enforcement constraints, $\bar{k}^{\alpha}-a_{i}^{\alpha}<\eta$. Similarly, being in the group with non-binding participation constraints implies $\underline{k}^{\alpha}-a_{i}^{\alpha}>\eta$. Finally, a necessary condition for being in the group where both constraints bind is given by $k_{i}^{\alpha}-a_{i}^{\alpha}=\eta$ for some $k_{i} \in[\underline{k}, \bar{k}]$. These three conditions are mutually exclusive and define the asset thresholds we need. The final part of the proposition now follows from the fact that all agents except those in the bottom group have a binding participation constraint.

Figure 3.2 shows the shape of the optimal capital allocation. Agents with low assets have a binding enforcement constraint, but strictly prefer to participate in the optimal arrangement. They all employ the same level $\underline{k}$ of capital which is the maximum level compatible with enforcement level $\eta$. Conversely, agents with high asset endowments have a binding participation constraint but a loose enforcement constraint. These agents operate at the highest 
level of capital $\bar{k}$. Agents in the middle have both constraints binding and operate with the capital stock such that their income level $k_{i}^{\alpha}-\eta$ exactly matches their autarky income.

The result implies that the optimal arrangement can be described by three equations that pin down the optimal level of enforcement $\eta$ and the optimal allocation of capital as described by the two cut-off points $\underline{a}$ and $\bar{a}$. Specifically

$$
\begin{aligned}
g^{\prime}(\eta) & =\int_{\left\{i \mid a_{i} \geq \bar{a}\right\}} \frac{1}{\alpha \bar{k}^{\alpha-1}} d i-\int_{\left\{i \mid a_{i}<\bar{a}\right\}} \frac{1}{\alpha k_{i}^{\alpha-1}} d i \\
g(\eta) & =E(a)-\int k_{i} d i \\
\eta & =\int\left(a_{i}^{\alpha}-\bar{a}^{\alpha}\right) d i .
\end{aligned}
$$

The first condition equates the marginal costs and the marginal benefits of enforcement. The right-hand side expresses the wedge between the marginal products of capital in the optimal allocation. Interestingly, this corresponds to the difference between the inverse of the marginal product of capital of unconstrained and constrained agents. ${ }^{15}$ The other two equations describe the feasibility of allocating capital and of transfers.

The final part of proposition implies that the optimal allocation leads to a more equal income distribution than under autarky. In particular, all agents above the initial endowment threshold $\underline{a}$ receive their autarkic income, while all other agents receive a fixed income higher than autarky. Hence, in this model, institutions that enable enforcement benefit primarily agents at the lower end of the wealth distribution.

Corollary 3.4. The optimal income distribution is a left-censored version of the income distribution under autarky.

Proof. Agent $i$ 's end-of-period income is $k_{i}^{\alpha}-t_{i}$ for all $i \in[0,1]$. All agents whose assets exceed $\underline{a}$ have a binding participation constraint. Hence, they have the same income as under autarky. Agents with endowments under $\underline{a}$ all realize income $\underline{k}^{\alpha}-\eta=\underline{a}^{\alpha}$.

It is instructive to compare the optimal allocation when enforcement is endogenous to the allocation that prevails when enforcement is costless and exogenous. In both cases, positive enforcement reduces the dispersion of marginal products vis-a-vis autarky by making capital

\footnotetext{
${ }^{15}$ This is reminiscent of an inverse Euler equation describing efficiency in the literature on Mirleesian taxation in dynamic economies. See e.g. Rogerson (1985) or Kocherlakota (2005).
} 
use constant past a certain asset threshold. The optimal allocation with an endogenous enforcement choice, however, also equates capital use among agents with low endowments. This suggests that the planner combines investment in enforcement institutions with some degree of redistribution of endowments when covering the costs of this investment. To make this idea precise, we now explain how the optimal allocation can be implemented with competitive capital markets.

\subsection{Implementing the Optimal Allocation}

When implementing the optimal allocation, it is necessary first of all to finance the introduction of enforcement at the optimal level $\eta$. We denote agent $i$ 's contribution to set up enforcement by $\kappa_{i}$. One could think of this as an entry fee (or subsidy when $\kappa_{i}<0$ ) paid from the initial endowment for participation in capital rental markets. After paying their fees, agents enter capital markets with endowments equal to $\hat{a}_{i}=a_{i}-\kappa_{i}$ and trade capital trade capital at a competitively determined rate $R$ subject to a borrowing constraint given by

$$
\left(k_{i}-\hat{a}_{i}\right) R \leq \eta
$$

The following results shows how the optimal allocation can be implemented via competitive markets.

Proposition 3.5. Let $(\eta, k, t)$ be the optimal allocation. Define $R=\alpha \bar{k}^{\alpha-1}$ and let $\kappa_{i}=$ $a_{i}-\left(k_{i}-\frac{t_{i}}{R}\right)$ for all $i$. Given the fee schedule $\left\{\kappa_{i} \mid i \in[0,1]\right\}$, competitive markets implement the optimal solution with the equilibrium interest rate given by $R$.

Proof. Let $\hat{a}_{i}=a_{i}-\kappa_{i}$ for all $i$ so that the total supply of capital available for production is $\int \hat{a}_{i} d i$. Then, the candidate allocation clears the capital market as

$$
\int \hat{a}_{i} d i=\int k_{i} d i-\frac{1}{R} \int t_{i} d i=\int k_{i} d i
$$

since $\int t_{i} d i=0$ at the planner's solution. Note that this also implies that the fee schedule $\kappa_{i}$ covers the cost $g(\eta)$.

We only have to verify that agent $i$ chooses the optimal capital input, $k_{i}$, at interest rate $R$. If agents are unconstrained, they will choose a capital level such that the marginal product is equal to $R$. Constrained agents, however, will choose a capital level that satisfies the constraint (3.11). 
Consider an agent with $a_{i}>\bar{a}$ who, therefore, is unconstrained in the optimal allocation. Then, $t_{i}<\eta$, and, by the definition of $\kappa_{i}$, the agent chooses $\bar{k}$ given $R$, as needed.

Agents with $a_{i} \leq \bar{k}$ are constrained in the optimal allocation so that $t_{i}=\eta$. By the definition of $\kappa_{i}$, this implies that $\hat{a}_{i}=k_{i}-\frac{\eta}{R}$. Hence, the agent chooses at most $k_{i}<\bar{k}$ given his borrowing constraint (3.11), as needed. This completes the proof.

One can interpret $\kappa_{i}$ as a tax schedule to finance the establishment of a capital market. As $\kappa$ increases with an agent's initial endowment, agents with high initial endowments finance a high share of the institutional cost. Moreover, for low enough initial endowment, we have that $\kappa<0$ so that poor agents receive a subsidy before markets open. Hence, as we surmised in the previous section, it is optimal to partially redistribute endowments before production begins. This redistribution allows the market to achieve a better allocation of capital. Participation constraints, however, impose an endogenous limit on how much endowment-rich agents can be taxed and, thus, on redistribution.

Even though the fee schedule is monotonic in initial wealth, the final result of this section establishes that it is not uniformally progressive.

Corollary 3.6. The fee schedule $\kappa_{i}$ is regressive for all $a_{i} \in[\underline{a}, \bar{a}]$ and progressive otherwise.

Proof. The definition of $\kappa_{i}$ implies

$$
\frac{\kappa_{i}}{a_{i}}= \begin{cases}1-\frac{1}{a_{i}}(\underline{k}-\eta / R) & \text { if } a_{i}<\underline{a} \\ 1-\frac{1}{a_{i}}\left[\left(a_{i}^{\alpha}+\eta\right)^{\frac{1}{\alpha}}-\eta / R\right] & \text { if } a_{i} \in[\underline{a}, \bar{a}] \\ 1-\frac{1}{a_{i}}\left[\bar{k}-\left(\bar{k}^{\alpha}-a_{i}^{\alpha}\right) / R\right] & \text { if } \quad a_{i} \geq \bar{a} .\end{cases}
$$

For $a_{i}<\underline{a}$ we then have

$$
\frac{\partial \kappa_{i} / a_{i}}{\partial a_{i}}=(\underline{k}-\eta / R) / a_{i}^{2}>a_{i}>0 .
$$

Next, for $a_{i} \in[\underline{a}, \bar{a}]$ we obtain

$$
\frac{\partial \kappa_{i} / a_{i}}{\partial a_{i}}=\frac{\eta}{a_{i}^{2}}\left[k_{i}^{1-\alpha}-\frac{1}{R}\right]
$$

By the definition of $R$, we have $1 / R=\bar{k}^{1-\alpha} / \alpha$. Hence,

$$
\frac{\partial \kappa_{i} / a_{i}}{\partial a_{i}}<0
$$


Finally, for $a_{i} \geq \bar{a}$,

$$
\frac{\partial \kappa_{i} / a_{i}}{\partial a_{i}}=\frac{(1-\alpha) a_{i}^{\alpha}}{R a_{i}^{2}}+\frac{\bar{k}}{a_{i}^{2}}\left(1-\frac{\bar{k}^{\alpha-1}}{R}\right) .
$$

Again using the fact that $\bar{k}=\left(\frac{\alpha}{R}\right)^{\frac{1}{1-\alpha}}$, we get

$$
\frac{\partial \kappa_{i} / a_{i}}{\partial a_{i}}=\frac{(1-\alpha)}{R a_{i}^{2}}\left(a_{i}^{\alpha}-\bar{k}^{\alpha}\right)>0 .
$$

\section{Inequality and Institutions}

In the one-input setting we have studied so far, more inequality in endowments implies a greater ex-ante dispersion in marginal products. Hence, one would expect that economies with more inequality should invest more resources in institutions providing enforcement, since the associated benefits are higher. To confirm this idea, we model rising inequality as follows. Let $a^{*}$ denote the average endowment. We say that the endowment schedule $\hat{a}=a+\delta\left(a-a^{*}\right)$ is more unequal than the distribution $a$ when $\delta>0$.

For our static problem, we now present three results - successively, more general - establishing that a more unequal schedule of endowment leads to a higher enforcement level. In this sense, economies with a greater dispersion in endowments and, hence, in marginal products before trade, are more likely to invest in institutions providing enforcement. We first look at the case where there are only two agents with different endowments. ${ }^{16}$

Proposition 4.1. Assume that there are two agents in all periods. When the distribution of endowments becomes more unequal, the optimal level of enforcement $\eta$ increases.

Proof. Write initial endowments in this case as $(a-\delta, a+\delta)$ where $a>0$ and $\delta \in[0, a)$. We denote the production function as $f$ and its inverse as $h$. Since $f$ is concave, $h$ is convex. We also denote capital use by the endowment poor agents by $k_{1}$, while $k_{2}$ denotes capital use by the rich agent.

Suppose the enforcement level is given by $\eta>0$. Then the capital allocation must solve

$$
k_{2}=h(f(a)-\eta)
$$

\footnotetext{
${ }^{16}$ It is straightforward to adapt the analysis of the previous section to this case.
} 
where $k_{2} \leq 2 a$. The agent with the low endowment then operates with capital $k_{1}=2 a-$ $h(f(a)-\eta)-g(\eta)$. Hence, total output is given by

$$
\Phi(\eta, \delta) \equiv f(a+\delta)-\eta+f(2 a-h(f(a)-\eta)-g(\eta))
$$

Note that the function $\Phi$ is strictly concave in $\eta$. The envelope theorem then implies that at the optimal level of enforcement

$$
\frac{\partial \eta}{\partial \delta}=-\frac{\Phi_{12}(\eta(\delta), \delta)}{\Phi_{11}(\eta(\delta), \delta)}
$$

Differentiating the function $\Phi$ with respect to $\eta$ we obtain

$$
\Phi_{1}(\eta(\delta), \delta)=-1+f^{\prime}\left(k_{1}\right)\left(h^{\prime}(f(a+\delta)-\eta)-g^{\prime}(\eta)\right)
$$

where $k_{1}=2 a-h(f(a+\delta)-\eta)-g(\eta)$ is the capital allocated to the low endowment agent.

We then have that

$$
\Phi_{11}(\eta(\delta), \delta)=f^{\prime \prime}\left(k_{1}\right)\left(h^{\prime}(\cdot)-g^{\prime}(\cdot)\right)^{2}-f^{\prime}\left(k_{1}\right)\left(h^{\prime \prime}(\cdot)+g^{\prime \prime}(\cdot)\right)<0,
$$

since $h$ is convex and $f$ is strictly increasing and concave. Furthermore, both $h$ and $h^{\prime}$ are increasing in $\delta$, as $f$ increases with $\delta$. This implies that $k_{1}$ decreases in $\delta$ and concavity of $f$ implies that $f^{\prime}\left(k_{1}\right)$ rises with $\delta$ too. Thus we obtain that

$$
\Phi_{12}(\eta(\delta), \delta)>0
$$

which completes the proof.

Returning to the case with a continuum of agents, suppose that the planner chooses to invest in strictly positive enforcement for a given the distribution of endowments. We now show that this remains the case if the distribution of endowments becomes more unequal.

Proposition 4.2. Assume that the planner opts for strictly positive enforcement for a given endowment distribution. This remains true when the endowment distribution becomes more unequal.

Proof. Let $k$ be the optimal capital allocation in the first economy while $\eta>0$ is the chosen degree of enforcement. We must have that $\int k_{i}^{\alpha} d i \geq \int a_{i}^{\alpha} d i$. 
Consider now the more unequal distribution of endowments described by $\hat{a}_{i}=a_{i}+\delta\left(a_{i}-\right.$ $\left.a^{*}\right)$. We will show that holding $\eta$ fixed a feasible capital allocation $\hat{k}$ exists in the more unequal economy such that $\int \hat{k}_{i}^{\alpha} d i \geq \int \hat{a}_{i}^{\alpha} d i$. Hence, strictly positive enforcement remains optimal for a more unequal distribution of endowments.

For all $i$, let

$$
\hat{k}_{i}^{\alpha}=k_{i}^{\alpha}+\hat{a}_{i}^{\alpha}-a_{i}^{\alpha}
$$

where it is assumed that $\delta$ is small enough that $\hat{k}_{i} \geq 0$ for all $i$. This is without loss of generality as the argument we use below is local. Leaving transfers unchanged, participation is clearly since it was in the original economy. The new allocation is better than autarky, since

$$
\int \hat{k}_{i}^{\alpha} d i=\int \hat{a}_{i}^{\alpha} d i+\int k_{i}^{\alpha} d i-\int a_{i}^{\alpha} d i \geq \int \hat{a}_{i}^{\alpha} d i .
$$

We are left to show that the new allocation satisfies the resource constraint. First, note that the total capital employed is given by

$$
\int \hat{k}_{i} d i=\int\left(\left(k_{i}^{\alpha}-a_{i}^{\alpha}\right)+\hat{a}_{i}^{\alpha}\right)^{1 / \alpha} d i
$$

Differentiating the integrand with respect to $\delta$ gives (up to multiplying constants)

$$
\left(\left(k_{i}^{\alpha}-a_{i}^{\alpha}\right)+\hat{a}_{i}^{\alpha}\right)^{1 / \alpha-1}\left(a_{i}+\delta\left(a_{i}-a^{*}\right)\right)^{\alpha-1}\left(a_{i}-a^{*}\right) .
$$

Hence, evaluating this expression at $\delta=0$ shows that small changes to $\delta$ do not increase the total capital employed provided

$$
\int\left(\frac{k_{i}}{a_{i}}\right)^{1-\alpha}\left(a_{i}-a^{*}\right) d i
$$

is weakly negative. We know that the original optimal allocation is such that $\left(\frac{k_{i}}{a_{i}}\right)^{1-\alpha}$ is a decreases as $i$ rises. Hence, by Chebyshev's integral inequality, we have

$$
\int\left(\frac{k_{i}}{a_{i}}\right)^{1-\alpha}\left(a_{i}-a^{*}\right) d i \leq \int\left(\frac{k_{i}}{a_{i}}\right)^{1-\alpha} d i \times \int\left(a_{i}-a^{*}\right) d i=0
$$

which completes the proof.

Finally, we now shows that the optimal level of enforcement rises with endowment in- 
equality in the specific case where the endowment distribution is symmetric around its mean. We relegate the proof to the appendix.

Proposition 4.3. Assume that the endowment distribution is symmetric around its mean. If the endowment distribution becomes more unequal, then the planner opts for no less enforcement.

We argue in the proof that if an increase in inequality led the planner to decrease the level of enforcement, it would be possible to construct an allocation that satisfies all constraints with the original distribution of endowments, but raises output, thereby contradicting the fact that the original allocation was optimal.

\section{The Dynamics of Enforcement, Wealth and Inequal- ity}

In the previous sections, we abstracted from any dynamic linkages. In this section, we focus on the interaction over time between wealth inequality and enforcement. In particular, we are interested in the long-run evolution of institutions providing enforcement and its impact on differences in wealth among agents over time. In order to keep the analysis tractable, we restrict our attention to simple inter-generational linkages.

Specifically, we assume that every period a member of lineage $i \in[0,1]$ agent of family $i \in[0,1]$ inherits as endowment a given fraction $\gamma_{i} \in[0,1]$ of their parent's income, where $\gamma_{i}$ is strictly increasing in $i$. We also maintain the assumption that investments in enforcement fully depreciate across periods.

Positing exogenously given intergenerational linkages is standard in most of the existing literature on inequality, growth and missing markets. ${ }^{17}$ There are at least two interpretations for such transfers: "warm-glow" altruism in the sense of Andreoni (1989), and intergenerational spillovers. The second interpretation is best understood if one thinks of productive resources in part as human capital. It has the advantage of side-stepping an obvious weakness of the warm-glow interpretation, namely the fact that lineages fail to internalize the consequences of their transfers on the welfare of their offspring. That concern is particularly strong in environments with redistribution policies. We thus emphasize the spillover interpretation and assume that generations are not linked in any other way. In particular, we will assume

\footnotetext{
${ }^{17}$ See for example Aghion and Bolton (1996), Banerjee and Newman (1993) or Benabou (1996).
} 
that generations are myopic about the dynamic effects of introducing institutions in the sense that they do not take into account the effect of the current enforcement choice on future generations' welfare.

If there is no enforcement technology, the only feasible allocation of capital is autarky in all periods. It follows directly that in that case the endowment of members of lineage $i$ converges geometrically to $\gamma_{i}^{\frac{1}{1-\alpha}}$ over time. Hence, the endowment distribution converges to the corresponding invariant distribution. ${ }^{18}$ We assume for simplicity that in period 0 , the distribution of endowments is this invariant distribution.

Suppose now that the possibility of investing in enforcement at a cost schedule given by $g$ is introduced. If the fixed cost is sufficiently large, no investment in enforcement is ever made, and the economy remains forever at the initial invariant distribution. To focus on the more interesting case, assume that the invariant distribution is sufficiently unequal that it is optimal to bear the fixed cost in period 0 . The next result states that under that assumption, bearing the fixed cost remains optimal in all subsequent periods, and that introducing enforcement leads to a progressive reduction of endowment inequality.

Proposition 5.1. If it is optimal to invest in enforcement at date $t=0$, then the optimal allocation features a positive enforcement level for all periods $t \geq 0$ that decreases over time. Furthermore, the economy converges monotonically to a long-run invariant distribution of income and endowments with progressively less inequality and higher output.

Proof. Denote the optimal enforcement level in period 0 by $\eta_{0}>0$ and let $a^{t}$ be the endowment function at date $t$. Recall that our assumptions on $g$ imply that it is never optimal to fully equate marginal products of capital. We first show that in period 1, the optimal positive level of enforcement in the previous period $\eta_{0}$ yields higher output than autarky $(\eta=0)$. Hence, enforcement will be at a strictly positive level. We then show that the new optimal level of enforcement in period 1 is strictly lower than the one in period 0 , or, equivalently, that $\eta_{1} \in\left(0, \eta_{0}\right)$. The desired result on the dynamics of enforcement will then follow by induction.

The optimal allocation at $t=0$ is described by equations (3.8)-(3.10). There are two cut-off points $\underline{a}^{0}=\underline{\gamma}_{0}^{\frac{1}{1-\alpha}}$ and $\bar{a}^{0}=\bar{\gamma}_{0}^{\frac{1}{1-\alpha}}$ determining capital and transfers given the optimal

\footnotetext{
${ }^{18}$ Note that the endowment distribution converges at a geometric rate to a single mass point if lineages bequeath the same fraction of their income regardless of whether institutional investments are made. Eventually then, output is at its maximum independently of the economy's history of institutional choices.
} 
level $\eta_{0}$. The new endowment function is then given for all $i \in[0,1]$ by

$$
a_{i}^{1}= \begin{cases}\gamma_{i} \underline{\gamma}_{0}^{\frac{\alpha}{1-\alpha}} & \text { if } \gamma_{i} \leq \underline{\gamma}_{0} \\ \gamma_{i}^{\frac{1}{1-\alpha}} & \text { if } \gamma_{i} \geq \underline{\gamma}_{0} .\end{cases}
$$

In particular, because $\gamma_{i} \underline{\gamma}_{0}^{\frac{\alpha}{1-\alpha}}>\gamma_{i}^{\frac{1}{1-\alpha}}=a_{i}^{0}$ whenever $\gamma_{i}<\underline{\gamma}_{0}$, we have that $E\left(a^{1}\right)>E\left(a^{0}\right)$.

Suppose first that we constrain the choice of enforcement to the level $\eta_{0}$ in period 1 . It is straightforward to verify that the optimal allocation of capital is still described by equations (3.9) and (3.10). In particular, the new upper endowment threshold $\bar{a}^{1}\left(\eta_{0}\right)$ is the same as in period 0 , while the lower threshold $\underline{a}^{1}\left(\eta_{0}\right)$ has to increase from its period 0 value, since the aggregate endowment has gone up $\left(E\left(a^{1}\right)>E\left(a^{0}\right)\right)$. These new thresholds pin down the new optimal allocation conditional on keeping the enforcement level at $\eta_{0}$.

We will now argue that this candidate allocation yields an average income level that exceeds its autarky counterpart at endowment distribution $a^{1}$, so that, in particular, it remains optimal to invest in positive enforcement in period 1. First note that the optimal allocation of capital $\left\{k_{i}^{0}: i \in[0,1]\right\}$ in period 0 is still feasible in period 1 given enforcement level $\eta_{0}$. Indeed, for any $i \in[0,1]$ such that $a_{i}^{0} \geq \underline{\gamma}_{0}^{\frac{1}{1-\alpha}}, a_{i}^{1}=a_{i}^{0}$ so the value of autarky is the same in period 0 and 1 . For any $i$ such that $a_{i}^{0}<\underline{\gamma}_{0}^{\frac{1}{1-\alpha}}$, we have

$$
\left(\underline{k}_{i}^{0}\right)^{\alpha}-\eta=\underline{\gamma}_{0}^{\frac{\alpha}{1-\alpha}}>\gamma_{i} \underline{\gamma}_{0}^{\frac{\alpha}{1-\alpha}}=a_{i}^{1}\left(\gamma_{i}\right)^{\alpha},
$$

as $\gamma_{i}<\underline{\gamma}_{0}$. This implies directly that in period 1 income is higher for everyone at the optimal period 0 allocation than it would be under autarky. As transfers sum to zero, aggregate output is also higher with enforcement than with autarky. Hence, it remains optimal to invest enforcement in period 1.

Next, we show that $\eta_{1}<\eta_{0}$. Evaluating the first-order condition (3.8) at the optimal capital allocation for the enforcement choice $\eta_{0}$ in period 1 , we obtain

$$
g^{\prime}\left(\eta_{0}\right)>\int_{\left\{i \mid a_{i} \geq \bar{a}\right\}} \frac{1}{\alpha\left[\bar{k}\left(\eta_{0}\right)\right]^{\alpha-1}} d i-\int_{\left\{i \mid a_{i}<\bar{u}\right\}} \frac{1}{\alpha\left[k_{i}\left(\eta_{0}\right)\right]^{\alpha-1}} d i \equiv f_{1}\left(\eta_{0}\right),
$$

or, in other words, that the marginal cost of enforcement exceeds the marginal benefits of enforcement at $\eta_{0}$ for the new aggregate endowment $E\left(a_{1}\right)$ in period 1 . Note that the righthand side of this equation describes the marginal benefits - denoted by the function $f_{1}(\eta)$ - 
of a given level of $\eta$ for the optimal allocation of capital associated with that level in period 1 .

From the concavity of the objective function and the strict convexity of the constraint set - which is ensured by our assumptions on $g$ conditional on incurring the fixed cost - we have a unique optimal value of enforcement $\eta_{1}$ that satisfies the first-order condition (3.8). Furthermore, for $\eta \rightarrow 0$ marginal benefits exceed marginal costs and for $\eta \rightarrow \infty$ the opposite is true. Hence, from the inequality above, it follows directly that the new optimal level of enforcement in period 1 decreases $\left(\eta_{1}<\eta_{0}\right)$ and that for all $\eta \in\left(\eta_{1}, \eta_{0}\right]$

$$
g^{\prime}(\eta)>f_{1}(\eta)
$$

To complete the proof, we show that lowering $\eta$ in period 1 to its new optimal level implies that the optimal cut-off points in period $1, \underline{a}_{1}$ and $\bar{a}_{1}$, both increase relative to their period 0 values. To do so, we look at how the optimal capital allocation conditional on a given level of $\eta$ changes in period 1 with changes in the enforcement level itself. Totally differentiating equation (3.10), we obtain

$$
\frac{d \bar{a}}{d \eta}=-\frac{1}{\alpha \bar{a}^{\alpha-1}(1-F(\bar{a}))}<0
$$

Since the upper tail of the endowment distribution in period 0 is identical to the one in period 1 , this implies that $\bar{a}_{1}>\bar{a}_{0}$. Next, totally differentiating equation (3.9) and using the result for $d \bar{a} / d \eta$, we obtain

$$
\frac{d \underline{a}}{d \eta}=-\frac{g^{\prime}(\eta)-f_{1}(\eta)}{\underline{a}^{\alpha-1}\left(\underline{a}^{\alpha}+\eta\right)^{\frac{1-\alpha}{\alpha}} F(\underline{a})},
$$

where $f_{1}(\eta)$ is defined above. Thus as long as $g^{\prime}(\eta)>f_{1}(\eta)$, decreasing $\eta$ increases the cut-off point. But we have established above that this is indeed the case for all $\eta \in\left(\eta_{1}, \eta_{0}\right]$. Hence, $\underline{a}_{1}>\underline{a}_{0}$.

We have then shown that the sequence of endowment distributions is a monotonically increasing sequence of distribution functions on $[0,1]$. Furthermore, we can bound the values of each distribution of the sequence below by 0 and above by $\gamma_{\max }^{\frac{1}{1-\alpha}}$. It then follows that the sequence of endowment distributions converges to some distribution as $t \rightarrow \infty$. Along this sequence, we have successively less inequality and higher output as marginal products become more equal. This completes the proof.

We have not addressed here the interaction between enforcement choice and growth rates 
where the latter depends endogenously on the evolution of productivity over time. When aggregate productivity growth from one period to the next depends on current aggregate output, choosing better institutions should have a permanent, positive effect on growth. To see why, assume as in Aghion et al. (1999) that agents in period $t$ can transform capital $k$ into output according to $A_{t} k^{\alpha}$ where $A_{t}>0$ measures aggregate productivity. The evolution of aggregate productivity is described by

$$
A_{t}=\int_{i} A_{t-1} k_{i, t-1}^{\alpha}
$$

for all $t>0$, where $k_{i, t}$ denotes the capital with which agent $i$ operates at date $t$ and the initial productivity level is normalized to $A_{0}=1$. Assuming that agents's individual endowments stay constant over time, the gross rate of output growth between periods $t-1$ and $t$ is then simply given by $\int_{i} k_{i, t}^{\alpha}$. Hence, the presence of institutions providing enforcement reduces the dispersion in capital use and, thus, growth is then permanently higher once enforcement becomes a choice variable.

\section{The Engerman-Sokoloff Hypothesis}

As we have argued, our framework predicts that economies with more endowment inequality should be quicker to invest in institutions conducive to trade, all else equal. This prediction seems puzzling in light for instance of the historical evidence for the Western Hemisphere surveyed by Engerman and Sokoloff (2002). This evidence suggests that human and physical capital were more highly concentrated in Latin America than in the United States and Canada.

Engerman and Sokoloff surmise that a highly concentrated distribution of human and physical capital could explain in part why the area was slow to implement institutions conducive to trade. They motivate this hypothesis primarily on politico-economic grounds. In this section we argue that the efficiency considerations we emphasize in this paper, far from casting doubt on this hypothesis, provide additional support for it.

To see this, it is necessary to augment our basic static model to include heterogeneity in both physical and human capital. Assume then that agents are born with a quantity $a_{i}>0$ of physical capital and a level $h_{i}>0$ of human capital for all $i \in[0,1]$ with the joint distribution of human and physical capital described by $\mu$. Agents are also endowed with a technology that transfers physical capital into consumption goods according to a Cobb-Douglas production 
function $h^{1-\alpha} k^{\alpha}$, where $h$ is the human capital of the agent and $\alpha \in(0,1)$. In other words, agents with more human capital are more productive and human capital cannot be traded across agents. Hence, the endowment of human capital acts like an agent-specific productivity parameter that is fixed.

For simplicity, we consider here only the case where the choice is between autarky and full enforcement. Full enforcement can be implemented at a fixed cost of $C>0$ units of capital before production starts. While we will not repeat the argument in this section, it is clear that an optimal allocation with enforcement can once again be implemented via competitive markets with a specific schedule of entry fees and subsidies. The fee schedule again has to satisfy all agents' participation constraint.

Since any transfer can be enforced when markets are complete, all participation constraints can be met if and only if aggregate output increases after the enforcement cost $C$ has been incurred. If there is no investment in enforcement, default cannot be punished hence all transfers are zero and autarky prevails. Aggregate output is then given by

$$
y^{A}=\int h^{1-\alpha} a^{\alpha} d \mu=E\left(h^{1-\alpha} a^{\alpha}\right)=E\left(h^{1-\alpha}\right) E\left(a^{\alpha}\right)+C O V\left(h^{1-\alpha}, a^{\alpha}\right) .
$$

On the other hand, when the planner bears cost $C$, markets are complete and the planner is able to equate marginal products across agents. Denoting the total endowment of human and physical capital by $\bar{h}$ and $\bar{k}$ respectively, we obtain, for all $i \in[0,1]$ :

$$
\frac{k_{i}}{h_{i}}=\frac{\bar{k}}{\bar{h}}
$$

Using aggregate resource feasibility, it follows then directly that full enforcement leads to aggregate output equal to

$$
y^{E}=\int h_{i}\left(\frac{\bar{k}}{\bar{h}}\right)^{\alpha} d \mu=\left(\int h d \mu\right)^{1-\alpha}\left(\int a d \mu-C\right)^{\alpha}=E(h)^{1-\alpha}(E(a)-C)^{\alpha} .
$$

Holding the endowment distribution of the other factor fixed, a mean preserving spread in either human capital or physical capital endowments lowers output under autarky without affecting the complete market outcome. Hence, as in the analysis with only physical capital, more inequality can lead to more investment in institutions, as the benefits from trade have increased. However, in this two-dimensional setting, for any given marginal distribution of physical and human capital, the correlation in the endowments of both factors of production 
also determines institutional investment. If endowment in human and physical capital is sufficiently positively correlated, aggregate output is higher under autarky and there is no institutional investment. The following results formalizes these ideas.

Proposition 6.1. Introducing complete markets with full enforcement at cost $C$ leads to higher output than under autarky if and only if

$$
E(h)^{1-\alpha}(E(a)-C)^{\alpha}-E\left(h^{1-\alpha}\right) E\left(a^{\alpha}\right)>C O V\left(h^{1-\alpha}, a^{\alpha}\right) .
$$

The intuition for this result is straightforward. In economies where both human and physical capital are highly concentrated, the gains from introducing institutions are small, as the marginal products of capital are not very unequally distributed. In fact, when $h$ and are $a$ are perfectly correlated, we have

$$
\operatorname{COV}\left(h^{1-\alpha}, a^{\alpha}\right)=E(h)^{1-\alpha} E(a)^{\alpha}-E\left(h^{1-\alpha}\right) E\left(a^{\alpha}\right)
$$

so that the inequality in Proposition 6.1 can never be met.

This result underscores the fact that it is inequality in marginal products before trade that matters for returns to institutional investments, not the overall endowment inequality per se. In the case of the Western Hemisphere, the fact that both human and physical capital have been highly concentrated historically in much of Latin America could explain why institutional quality has lagged behind its counterpart in the United States or Canada. In environments where physical and human capital endowments are highly correlated, institutions conducive to trading physical resources may not have much effect on output and growth, unless resource poor individuals are able to acquire more human capital. We have abstracted here from dynamic considerations in the form of investment into human (and physical) capital, but future work on the long-run implications of such a theory will be interesting.

\section{Limited Commitment and Redistribution}

Market economies often employ systems of ex-post income redistribution. ${ }^{19}$ When analyzing investment in institutions that enable market exchange of capital, we have assumed that the planner levies a fee schedule to finance the cost of enforcement $g$, but does not redistribute

\footnotetext{
${ }^{19}$ One can argue that democracies tend to be positively correlated with market economies, but also with formal tax systems that redistribute income based on market outcomes.
} 
income further ex-post. This implies that as long as the fee schedule satisfies the ex-ante participation constraint of agents, they will pay the fee to finance the investment in enforcement. The fee itself is set optimally to achieve efficiency.

Instead, we assume in this section that the planner has a preference for equalizing consumption across agents and that he cannot commit ex-ante - when financing the enforcement technology - to specific transfers after production has taken place. ${ }^{20}$ We choose the same set-up as in the previous section, but restrict endowments to physical capital. Again, there is a discrete choice of introducing full enforcement for a fixed cost $C$.

Let $\tau=\left\{\tau_{i}: i \in[0,1]\right\}$ be the fee schedule that is used at the beginning of the period (before production) to invest in enforcement, while $t=\left\{t_{i}: i \in[0,1]\right\}$ still denotes transfers after production has taken place. ${ }^{21}$ Since contributions are sunk, the value of agent $i$ 's outside option becomes

$$
\hat{a}_{i}^{\alpha}=\left(a_{i}-\tau_{i}\right)^{\alpha}
$$

for all $i \in[0,1]$ once enforcement has been financed. Note that the fee schedule $\tau$ is feasible as long as

$$
\int \tau_{i} d i \geq C
$$

Finally, we call a fee schedule $\tau$ incentive compatible, if the ex-post income of all agents after fees $\tau$ and transfers $t$ is at least as high as the ex-ante income with autarky $a^{\alpha}$.

Once enforcement is introduced, it is efficient to equate marginal products of capital yielding aggregate output equal to $y^{E}=(E(a)-C)^{\alpha}=\bar{k}^{\alpha}$. Given enforcement has been introduced and financed via a fee schedule $\tau$, the planner will choose a transfer schedule $t$ to solve

$$
\max \int u\left(\bar{k}^{\alpha}-t_{i}\right) d i
$$

subject to

$$
\begin{aligned}
\int t_{i} d i & =0 \\
\bar{k}^{\alpha}-t_{i} & \geq \hat{a}^{\alpha} \text { for almost all } i .
\end{aligned}
$$

\footnotetext{
${ }^{20}$ This is then somewhat reminiscent of the approach taken by Acemoglu et al. (2007). It also adds an element of political economy considerations to our approach. See also Rajan (2007) who shows that persistent underdevelopment can be explained by the fact that rich people cannot necessarily reap the benefits from institutional investment.

${ }^{21}$ Note that the fees charged here will be different from the schedule $\kappa_{i}$ used in our previous implementation result.
} 
The solution is given by a cut-off level $\underline{\hat{a}}$ below which all agents are unconstrained and receive the same consumption level $\bar{k}^{\alpha}-\bar{t}$ that exceeds autarky taking into account $\tau$.

However, this puts restrictions on the fee schedule. Agents that receive higher consumption than the minimum level cannot be taxed upfront in order to finance enforcement. For any $\tau_{i}>0$ we have that $\hat{a}^{\alpha}<a^{\alpha}$, and agents are better off staying in autarky from the beginning, if they have initial wealth above $\underline{\hat{a}}$. Furthermore, as the planner wants to equate consumption ex-post, it is never optimal to subsidize agents with high initial endowment. In other words, there exists a cut-off level of initial endowment $\underline{a}$ such that $\tau_{i}=0$ and $t_{i}<\bar{t}$ whenever $a \geq \underline{a}$.

Thus, only agents that are unconstrained at the minimum ex-post consumption level can be taxed in order to finance enforcement. Their initial endowment is limited at $\int_{\{i \mid a \leq \underline{a}\}} a d i$. This introduces an additional financing restriction on the planner's problem leading to the following result.

Proposition 7.1. Suppose aggregate output with full enforcement at fixed cost $C$ exceeds output with autarky. If the planner cannot commit to an ex-post transfer schedule $t$, the initial investment in enforcement can be financed only if

$$
\int_{\{i \mid a \leq \underline{a}\}} a d i \geq C
$$

where $\underline{a}$ is the maximum endowment level where agents receive the constant minimum level of consumption with full enforcement.

This result is intriguing. As soon as the planner cannot commit anymore to a particular transfer scheme ex-post, only agents at the lower end of the wealth distribution can be taxed to finance institutions. Levying a tax on wealthy agents and promising to reimburse them for this tax through transfers when capital is being exchanged is not credible. It is important to note that this result does not depend on using the enforcement technology to extract additional resources from agents after the institution has been set-up. It arrives purely from the lack of a commitment to a particular transfer scheme that could reimburse agents for their initial investment. Hence, economies with an extreme inequality of wealth tend to face additional barriers to introduce institutions that enable higher output and growth. Agents that have enough endowment to finance good institutions might not have an incentive to do so as they cannot reap a return from investing. Introducing a time-consistency problem on the planner sheds thus some light on the question why economies with high inequality can be stuck with persistently bad institutions. 


\section{Concluding remarks}

In much of the recent literature on inequality and growth, it is the combination of inequality and market imperfections that potentially lead to an adverse outcome. This, as the literature has emphasized, creates a potential rationale for redistribution. In this paper, we have pointed out that as long as it is possible to invest in better functioning markets, the optimal policy typically calls for a combination of redistribution and institution-building. In other words, a natural prediction of recent models of inequality and growth is that economies with more inequality should invest more resources in institutions conducive to trade, simply because more ex-ante inequality raises the benefits of trade.

However, here as wherever inequality is the object of interest, it is critical to recognize that it is ex-ante inequality in marginal products that matters for returns to various policies, not endowment inequality per se. We have shown in this paper that endowment inequality may in fact be associated with very little inequality in marginal products, hence low returns to institutional building.

In the case of the Western Hemisphere, the fact that both human and physical capital have been highly concentrated historically in much of Latin America could explain why institutional quality has lagged behind its counterpart in the United States or Canada. In environments where physical and human capital endowments are highly correlated, institutions conducive to trading physical resources may not have much effect on growth rates unless resource-poor individuals acquire more human capital.

Our results also have several implications for the ongoing debate on the relative importance of human capital and institutional quality for economic development (see e.g. Glaeser et al. (2004) or Galor and Moav (2006)). The results suggest that the two are intimately related. Investments in human capital raise the returns to investments in institutions. Conversely, better institutions enable nations to direct physical resources to their most productive use, which raises returns to human capital development. Under those circumstances, the question of whether institution quality or human capital is the key to development success may be immaterial. 


\section{Appendix}

\subsection{Concave Objective Function}

The objective of this first appendix is to show that when the planner has maximizes a strictly concave objective function, he chooses the same allocation of capital and consumption as he would with a linear objective. Denoting the endowment distribution by $F$ and the planner's strictly concave, continuously differentiable welfare functional by $u$, the planner's problem is:

$$
\max _{(k, t, \eta)} \int u\left(k(a)^{\alpha}-t(a)\right) d F(a)
$$

subject to:

$$
\begin{aligned}
\int k(a) d F(a)+g(\eta) & \leq \int a d F(a) \\
k(a)^{\alpha}-t(a) & \geq a^{\alpha} \text { for all } a \\
t(a) & \leq \eta \text { for all } a \\
\int t(a) d F(a) & \geq 0
\end{aligned}
$$

Assuming an interior solution, necessary and sufficient conditions are

$$
\begin{aligned}
{\left[u^{\prime}(\cdot)+\nu^{0}(a)\right] \alpha k^{\alpha-1}-\lambda } & =0 \\
-u^{\prime}(\cdot)-\nu^{0}(a)-\nu^{1}(a)+\mu & =0 \\
-\lambda g^{\prime}(\eta)+\int \nu^{1}(a) d F(a) & =0 .
\end{aligned}
$$

where $\nu^{0}$ and $\nu^{1}$ are the Lagrange multipliers on the participation and enforcement constraints, respectively. Note that in the context of this section, these multipliers are normalized by the endowment density $f$.

It follows immediately that for any optimal allocation, the resource constraint and the nonnegativity constraint on transfers must bind. Hence, $\lambda>0$ and $\mu>0$. Similarly, assuming no fixed costs and convexity for enforcement costs (i.e., $g(0)=0$ and $g^{\prime}(0)=0$ to be precise), we have that $\eta>0$, whenever $F(a)$ is not degenerate. Also, by equation (9.7) it must be the case that the enforcement constraint binds for some positive mass of endowments. 
The first two conditions can be conveniently rewritten as

$$
\begin{aligned}
\lambda & =\left[\nu^{0}(a)+u^{\prime}(\cdot)\right] \alpha k(a)^{\alpha-1} \\
\mu & =\nu^{1}(a)+\lambda \frac{1}{\alpha} k^{1-\alpha}
\end{aligned}
$$

The first equation determines consumption, while the second determines the capital input. Next, we distinguish between several cases that will be relevant for characterizing the optimal allocation.

$\underline{\text { Case } 1 \text { - Slack enforcement constraint }}$

In this case, we have that a unique $\bar{k}$ that solves

$$
\frac{\lambda}{\mu}=\alpha k^{\alpha-1}
$$

which is the same for all $a$ at which the enforcement constraint is slack. Note that the participation constraint does not matter for this result. Note also that $\bar{k}$ is the maximum $k$ that will be allocated to any $a$, i.e. $\max _{a} k(a)=\bar{k}$.

Case 2 - Slack participation constraint, but binding enforcement constraint

In this case, $t=\eta$ and

$$
\lambda k^{1-\alpha}=\alpha u^{\prime}\left(k^{\alpha}-\eta\right)
$$

The left-hand side is increasing in $k$, while the concavity of $u$ implies that the right-hand side is increasing in $k$. Hence, there can be at most one solution to this equation. We call it $\underline{k}$.

$\underline{\text { Case } 3 \text { - Both constraints bind }}$

Then, $k$ is an increasing function of $a$ given by

$$
k(a)=\left(a^{\alpha}+\eta\right)^{\frac{1}{\alpha}} .
$$

Of course, $k(a) \leq \bar{k}$.

Claim: The enforcement and the participation constraint cannot both be slack.

Note first the when both constraints are slack at endowment level $a$, capital is the highest 
at $\bar{k}$, but consumption the lowest. The first follows from Case 1 above. As for the second, suppose otherwise. Then, there exists some $\tilde{a}<a$ where consumption is lower. But one can then increase $t(a)$ and decrease $t(\tilde{a})$ a the same small amount to increase welfare, which is feasible since the participation constraint is slack at $a$.

Now, suppose to the contrary that both constraints are slack. Since capital is at its highest while consumption is at its lowest, it must be the case that transfer is at its highest as well. But we have assumed that the enforcement is not binding, which implies that it is not binding for any $a$, which is the desired contradiction.

Finally, let us determine the shape of $k(a)$. For any $a$ where enforcement constraint is slack, we must have that $\bar{k}^{\alpha}-t=a^{\alpha}$. Define $\bar{a}$ by $\bar{k}^{\alpha}-\eta=\bar{a}^{\alpha}$. Then from the claim above, it must be the case that the enforcement constraint binds for all $a \leq \bar{a}$.

Now define a second cut-off point by $\underline{k}^{\alpha}-\eta=\underline{a}^{\alpha}$. Clearly, $\underline{a}<\bar{a}$. Suppose now that for $\tilde{a}<\underline{a}$, the participation constraint binds. As the enforcement constraint also binds, we have that

$$
u^{\prime}\left(\tilde{a}^{\alpha}\right) k \tilde{a}^{\alpha-1}<\frac{\lambda}{\alpha}=u^{\prime}\left(\underline{a}^{\alpha}\right) k \underline{a}^{\alpha-1}
$$

which is a contradiction as both $\tilde{a}<\underline{a}$ and $k(\tilde{a})<k(\underline{a})$.

Conclusion 1: For $[0, \underline{a}]$, only the enforcement constraint binds and capital is constant at $\underline{k}$.

Next, for $\bar{a}>a>\underline{a}$ the enforcement constraint binds. It follows that the participation constraint must bind, as otherwise we have $a^{\alpha}>\underline{k}^{\alpha}-\eta$.

Conclusion 2: For $[\underline{a}, \bar{a}]$, both constraints bind and capital is increasing according to the function $k(a)=\left(a^{\alpha}+\eta\right)^{\frac{1}{\alpha}}$.

Finally, suppose for some $\tilde{a}>\bar{a}$, we have that the enforcement constraint binds. Then, we have from the participation constraint that

$$
k(\tilde{a})-\eta \geq \tilde{a}^{\alpha}>\bar{a}^{\alpha}=\bar{k}^{\alpha}-\eta
$$

implying that $k(\tilde{a})>\bar{k}$ which is a contradiction given the definition of $\bar{k}$. Hence, the enforcement constraint cannot bind which implies that the participation constraint has to bind.

Conclusion 3: For $[\bar{a}, \infty)$, only the participation constraint is binding. Capital is constant at $\bar{k}$. 
Finally, we show that the two cut-off points and, hence, the optimal capital allocation is identical to the problem where the planner maximizes output. Note first, that there are three regions as before that depend on which constraints bind. Second, the characterization of the optimal capital allocation is given by three equations: (i) the first-order condition with respect to $\eta$, (ii) the feasibility constraint and (iii) the constraint that aggregate transfers sum to 0 . These equations determine three variables $(\eta, \bar{a}, \underline{a})$. After some algebra, the three equations are

$$
\begin{aligned}
g^{\prime}(\eta) & =\frac{1}{\alpha} \bar{k}^{1-\alpha} F(\bar{a})-\frac{1}{\alpha} \underline{k}^{1-\alpha} F(\underline{a})-\int_{\underline{a}}^{\bar{a}}\left(a^{\alpha}+\eta\right)^{\frac{1-\alpha}{\alpha}} f(a) d a \\
g(\eta) & =E(a)-\left[\underline{k} F(\underline{a})+\bar{k}(1-F(\bar{a}))+\int_{\underline{a}}^{\bar{a}}\left(a^{\alpha}+\eta\right)^{\frac{1}{\alpha}} f(a) d a\right] \\
0 & =\eta F(\bar{a})+\bar{k}^{\alpha}(1-F(\bar{a}))-\int_{\bar{a}}^{\infty} a^{\alpha} f(a) d a
\end{aligned}
$$

where $\bar{k}$ and $\underline{k}$ are defined by $\eta$ and the two cut-offs in $a$. Obviously, the last two must be the same as in the problem with output maximization. Also, the first one (a first-order condition) does not depend on $u$ and is identical to the first-order condition for $\eta$ in the other problem. The consumption allocation also stays the same. In other words, when the planner maximizes total output, he also achieves the highest level of redistribution that is feasible.

The intuition for this invariance result is simple. As the capital allocation remains unchanged, agents below $\underline{a}$ receive the minimum consumption level given by $\underline{k}-\eta$ irrespective of their initial endowment $a$. All the other agents obtain a consumption level that equals their outside option $a^{\alpha}$.

\subsection{Proof of Proposition 4.3}

Suppose the distribution of endowments is symmetric around the mean $a^{*}$, so that the full enforcement efficient level of capital is $a^{*}$ for all agents. Note that this assumption implies a lower bound $a^{l}$ and an upper bound $a^{h}$ on the distribution of endowment since we only consider positive endowments. Consider a (small) mean preserving spread of the original distribution of the type $\hat{a}_{i}=a_{i}+\delta\left(a_{i}-a^{*}\right)$. Note that symmetry of the distribution implies $\int \hat{a}_{i} d i=\int a_{i} d i=a^{*}$. Let $\left(\eta_{\delta}, \hat{k}, \hat{t}\right)$ denote the solution to the planner's problem for this new distribution. Suppose that $\eta_{\delta}<\eta$. We want to show that $\eta$, is then not optimal for the original distribution. Recall that the solution to the planner's problem has the following 
form:

$$
k_{i}^{\alpha}-t_{i}=\left\{\begin{array}{lll}
\underline{k}^{\alpha}-\eta & \text { if } & a_{i} \leq \underline{a}(\eta) \\
a_{i}^{\alpha} & \text { if } & a_{i} \geq \underline{a}(\eta)
\end{array}\right.
$$

We assume that $\delta$ is small enough that $\underline{\hat{a}}\left(\eta_{\delta}\right)>a^{l}$ and $\bar{a}\left(\eta_{\delta}\right)<a^{h}$. Note that if the planner implements $\eta$ as a level of enforcement for the new distribution, then the threshold $\underline{a}^{\prime}(\eta)=\underline{a}(\eta)+\delta\left(\underline{a}(\eta)-a^{*}\right)$ is feasible. Indeed, we only need to check that

$$
\int_{a^{l}+\delta\left(a^{l}-a^{*}\right)}^{a^{h}+\delta\left(a^{h}-a^{*}\right)} k^{\prime}(a) d G(a)+g(\eta)=a^{*}
$$

for some capital allocation and transfers $\left(k^{\prime}\right.$ and $t^{\prime}$ defined on the range $\left[a^{l}+\delta\left(a^{l}-a^{*}\right), a^{h}+\delta\left(a^{h}-a^{*}\right)\right]$ such that

$$
k_{i}^{\prime \alpha}-t_{i}^{\prime}=\left\{\begin{array}{lll}
\underline{k}^{\alpha}-\eta & \text { if } & a_{i} \leq \underline{a}^{\prime}(\eta) \\
a_{i}^{\alpha} & \text { if } & a_{i} \geq \underline{a}^{\prime}(\eta)
\end{array}\right.
$$

Set $k^{\prime}(a)=k\left(\frac{a_{i}+\delta a^{*}}{1+\delta}\right)$ and $t^{\prime}(a)=t\left(\frac{a_{i}+\delta a^{*}}{1+\delta}\right)$, where $k(a), t(a)$ is the original allocation. We have

$$
\begin{aligned}
& \int_{a^{l}+\delta\left(a^{l}-a^{*}\right)}^{a^{h}+\delta\left(a^{h}-a^{*}\right)} k^{\prime}(a) d G(a)+g(\eta)=\int_{a^{l}+\delta\left(a^{l}-a^{*}\right)}^{\underline{a}^{\prime}(\eta)} k^{\prime}(a) d G(a)+\int_{\underline{a}^{\prime}(\eta)}^{a^{h}+\delta\left(a^{h}-a^{*}\right)} k^{\prime}(a) d G(a)+g(\eta) \\
& =\int_{a^{l}+\delta\left(a^{l}-a^{*}\right)}^{\left.\underline{a}(\eta)+\delta(\underline{a})-a^{*}\right)} k\left(\frac{a+\delta a^{*}}{1+\delta}\right) d F\left(\frac{a+\delta a^{*}}{1+\delta}\right) \\
& +\int_{\underline{a}(\eta)+\delta\left(\underline{a}(\eta)-a^{*}\right)}^{a^{h}+\delta\left(a^{h}-a^{*}\right)} k\left(\frac{a+\delta a^{*}}{1+\delta}\right) d F\left(\frac{a+\delta a^{*}}{1+\delta}\right)+g(\eta) \\
& =\int_{a^{l}}^{\underline{a}(\eta)} k(a) d F(a)+\int_{\underline{a}(\eta)}^{a^{h}} k(a) d F(a)+g(\eta) \\
& =a^{*} \text {. }
\end{aligned}
$$

Also note that

$$
\begin{aligned}
\int_{a^{l}+\delta\left(a^{l}-a^{*}\right)}^{a^{h}+\delta\left(a^{h}-a^{*}\right)} \hat{k}(a)^{\alpha}-\hat{t}(a) d G(a) & =\int_{a^{l}+\delta\left(a^{l}-a^{*}\right)}^{\underline{a}\left(\eta_{\delta}\right)} \underline{a}\left(\eta_{\delta}\right)^{\alpha} d G(a)+\int_{\underline{a}(\eta \delta)}^{a^{h}+\delta\left(a^{h}-a^{*}\right)} a^{\alpha} d G(a) \\
& >\int_{a^{l}+\delta\left(a^{l}-a^{*}\right)}^{\underline{a}^{\prime}(\eta)} \underline{a}^{\prime}(\eta)^{\alpha} d G(a)+\int_{\underline{a}^{\prime}(\eta)}^{a^{h}+\delta\left(a^{h}-a^{*}\right)} a^{\alpha} d G(a)
\end{aligned}
$$

where the inequality follows from the fact that the planner chose enforcement level $\eta_{\delta}$ and not 
$\eta$ (choosing $\eta$, we have to show that the threshold $\underline{a}^{\prime}(\eta)$ is feasible for the planner). Hence, for all $\delta, \underline{a}\left(\eta_{\delta}\right)>\underline{a}^{\prime}(\eta)=\underline{a}(\eta)+\delta\left(\underline{a}(\eta)-a^{*}\right)$. Taking the limit as $\delta$ goes to zero, $\underline{a}\left(\eta_{\delta}\right) \geq \underline{a}(\eta)$. Therefore, $\underline{a}\left(\eta_{\delta}\right) \geq \underline{a}(\eta)$, holds for all $\delta$ in some neighborhood $\mathcal{O}$ of zero. We now assume that $\delta$ belongs to this neighborhood.

Since $\left(\eta_{\delta}, \hat{k}, \hat{t}\right)$ solve the planner's problem, it must be the case that these two constraints are satisfied (in particular for those agents $i$ with endowments $a_{i} \in\left[a^{l}, a^{h}\right]$ )

$$
\begin{aligned}
\hat{k}_{i}^{\alpha}-\hat{t}_{i} & \geq a_{i}^{\alpha} \text { for almost all } i \\
\hat{t}_{i} & \leq \eta_{\delta} \text { for almost all } i
\end{aligned}
$$

Also, the resource constraint implies, with a change of variable

$$
\begin{aligned}
& \int_{a^{l}+\delta\left(a^{l}-a^{*}\right)}^{a^{h}+\delta\left(a^{h}-a^{*}\right)} \hat{k}\left(a_{i}\right) d G\left(a_{i}\right)+g\left(\eta_{\delta}\right)=a^{*} \\
& \int_{a^{l}+\delta\left(a^{l}-a^{*}\right)}^{a^{h}+\delta\left(a^{h}-a^{*}\right)} \hat{k}\left(a_{i}\right) d F\left(\frac{a_{i}+\delta a^{*}}{1+\delta}\right)+g\left(\eta_{\delta}\right)=a^{*} \\
& \int_{a^{l}}^{a^{h}} \hat{k}\left(a_{i}+\delta\left(a_{i}-a^{*}\right)\right) d F\left(a_{i}\right)+g\left(\eta_{\delta}\right)=a^{*} .
\end{aligned}
$$

Therefore, using the policy $\left(\hat{k}_{i}\right)_{i}$ and $\eta_{\delta}$ is feasible under the original distribution. For any $a_{i} \in\left[a^{l}, a^{h}\right]$, and the original distribution $F($.$) we use now the allocation given by$ $\hat{k}\left(a_{i}+\delta\left(a_{i}-a^{*}\right)\right)$ and $\eta_{\delta}$.

To check incentive compatibility we need to check that there is a function $\tilde{t}\left(a_{i}\right)$ such that $\hat{k}\left(a_{i}+\delta\left(a_{i}-a^{*}\right)\right)^{\alpha}-\tilde{t}\left(a_{i}\right) \geq a_{i}^{\alpha}$. Note that $\hat{k}\left(a_{i}+\delta\left(a_{i}-a^{*}\right)\right)^{\alpha}-\hat{t}\left(a_{i}+\delta\left(a_{i}-a^{*}\right)\right) \geq$ $\left(a_{i}+\delta\left(a_{i}-a^{*}\right)\right)^{\alpha}$. However since $a_{i}+\delta\left(a_{i}-a^{*}\right) \lesseqgtr a_{i}$ for $a_{i} \lesseqgtr a^{*}, \hat{k}\left(a_{i}+\delta\left(a_{i}-a^{*}\right)\right)^{\alpha}-$ $\hat{t}\left(a_{i}+\delta\left(a_{i}-a^{*}\right)\right) \geq a_{i}^{\alpha}$ may not be satisfied for $a_{i}<a^{*}$. For all $a_{i}$ set $\tilde{t}\left(a_{i}\right)$ such that $\tilde{t}\left(a_{i}\right)=$ $\min \left\{\hat{k}\left(a_{i}+\delta\left(a_{i}-a^{*}\right)\right)^{\alpha}-a_{i}^{\alpha} ; \eta_{\delta}\right\}$. By construction, incentive compatibility is satisfied, and there is a level $\underline{\hat{a}}\left(\eta_{\delta}\right)$ such that $\tilde{t}\left(a_{i}\right)=\eta_{\delta}$, for all $a_{i}<\underline{\hat{a}}\left(\eta_{\delta}\right)$. We now need to check that $\int_{a^{l}}^{a^{h}} \tilde{t}_{i}\left(a_{i}\right) d F\left(a_{i}\right) \geq 0$. Note that $\underline{\hat{a}}\left(\eta_{\delta}\right)=\underline{a}\left(\eta_{\delta}\right)$. The reason is that by the definition of $\underline{a}\left(\eta_{\delta}\right)$ we have $\hat{k}(a)^{\alpha}-\eta_{\delta}=\underline{a}\left(\eta_{\delta}\right)^{\alpha}$ for all $a<\underline{a}\left(\eta_{\delta}\right)^{\alpha}$. Hence, since $\underline{a}\left(\eta_{\delta}\right)+\delta\left(\underline{a}\left(\eta_{\delta}\right)-a^{*}\right)<\underline{a}\left(\eta_{\delta}\right)$, $\hat{k}\left(\underline{a}\left(\eta_{\delta}\right)+\delta\left(\underline{a}\left(\eta_{\delta}\right)-a^{*}\right)\right)^{\alpha}-\eta_{\delta}=\underline{a}\left(\eta_{\delta}\right)^{\alpha}$. This also holds for all $a<\underline{a}\left(\eta_{\delta}\right)$. Also, for all $a>\underline{a}\left(\eta_{\delta}\right)$ such that $a+\delta\left(a-a^{*}\right) \leq \underline{a}\left(\eta_{\delta}\right)$, we know that $\hat{k}\left(\underline{a}\left(\eta_{\delta}\right)+\delta\left(\underline{a}\left(\eta_{\delta}\right)-a^{*}\right)\right)^{\alpha}-\eta_{\delta}=$ 
$\underline{a}\left(\eta_{\delta}\right)^{\alpha}<a^{\alpha}$. Therefore, $\underline{\hat{a}}\left(\eta_{\delta}\right)=\underline{a}\left(\eta_{\delta}\right)$. Thus,

$$
\int_{a^{l}}^{a^{h}} \tilde{t}_{i}\left(a_{i}\right) d F\left(a_{i}\right)=\int_{a^{l}}^{\underline{a}\left(\eta_{\delta}\right)} \eta_{\delta} d F\left(a_{i}\right)+\int_{\underline{a}\left(\eta_{\delta}\right)}^{a^{h}}\left[\hat{k}\left(a_{i}+\delta\left(a_{i}-a^{*}\right)\right)^{\alpha}-a_{i}^{\alpha}\right] d F\left(a_{i}\right)
$$

and we get

$$
\begin{array}{rl}
\int_{a^{l}}^{\underline{a}\left(\eta_{\delta}\right)} & \eta_{\delta} d F\left(a_{i}\right)+\int_{\underline{a}\left(\eta_{\delta}\right)}^{a^{h}}\left[\hat{k}\left(a_{i}+\delta\left(a_{i}-a^{*}\right)\right)^{\alpha}-a_{i}^{\alpha}\right] d F\left(a_{i}\right)= \\
= & \int_{a^{l}}^{\underline{a}\left(\eta_{\delta}\right)} \eta_{\delta} d F\left(a_{i}\right)+\int_{\underline{a}\left(\eta_{\delta}\right)}^{a^{h}}\left[\hat{k}\left(a_{i}+\delta\left(a_{i}-a^{*}\right)\right)^{\alpha}-\hat{t}\left(a_{i}+\delta\left(a_{i}-a^{*}\right)\right)-a_{i}^{\alpha}\right] d F\left(a_{i}\right) \\
& \quad+\int_{\underline{a}\left(\eta_{\delta}\right)}^{a^{h}} \hat{t}\left(a_{i}+\delta\left(a_{i}-a^{*}\right)\right) d F\left(a_{i}\right) \\
= & \int_{a^{l}}^{a^{h}} \hat{t}\left(a_{i}+\delta\left(a_{i}-a^{*}\right)\right) d F\left(a_{i}\right)+\int_{\underline{a}\left(\eta_{\delta}\right)}^{a^{h}}\left\{\left[a_{i}+\delta\left(a_{i}-a^{*}\right)\right]^{\alpha}-a_{i}^{\alpha}\right\} d F\left(a_{i}\right) \\
\geq 0 & 0
\end{array}
$$

for $\delta$ close enough to zero using symmetry of the endowment distribution. So, the policy $\left(\eta_{\delta}, \hat{k}, \tilde{t}\right)$ is feasible for the original distribution. Also we showed earlier in the proof that $\underline{a}\left(\eta_{\delta}\right) \geq \underline{a}\left(\eta_{\delta}\right)$ for $\delta \in \mathcal{O}$. Therefore,

$$
\begin{aligned}
& \int_{a^{l}}^{a^{h}} \hat{k}\left(a_{i}+\delta\left(a_{i}-a^{*}\right)\right)^{\alpha}-\tilde{t}\left(a_{i}\right) d F\left(a_{i}\right)= \\
& =\int_{a^{l}}^{\underline{a}\left(\eta_{\delta}\right)} \hat{k}\left(a_{i}+\delta\left(a_{i}-a^{*}\right)\right)^{\alpha}-\tilde{t}\left(a_{i}\right) d F\left(a_{i}\right)+\int_{\underline{a}\left(\eta_{\delta}\right)}^{a^{h}} \hat{k}\left(a_{i}+\delta\left(a_{i}-a^{*}\right)\right)^{\alpha}-\tilde{t}\left(a_{i}\right) d F\left(a_{i}\right)= \\
& =\int_{a^{l}}^{\underline{a}\left(\eta_{\delta}\right)} \hat{k}\left(a_{i}+\delta\left(a_{i}-a^{*}\right)\right)^{\alpha}-\tilde{t}\left(a_{i}\right) d F\left(a_{i}\right)+\int_{\underline{a}\left(\eta_{\delta}\right)}^{a^{h}} a^{\alpha} d F\left(a_{i}\right)= \\
& =\int_{a^{l}}^{\underline{a}\left(\eta_{\delta}\right)} \hat{k}\left(a_{i}+\delta\left(a_{i}-a^{*}\right)\right)^{\alpha}-\eta_{\delta} d F\left(a_{i}\right)+\int_{\underline{a}\left(\eta_{\delta}\right)}^{a^{h}} a^{\alpha} d F\left(a_{i}\right)= \\
& =\int_{a^{l}}^{\underline{a}\left(\eta_{\delta}\right)}\left[\hat{k}\left(a_{i}+\delta\left(a_{i}-a^{*}\right)\right)^{\alpha}-\eta_{\delta}\right] d F\left(a_{i}\right)+\int_{\underline{a}\left(\eta_{\delta}\right)}^{a^{h}} a^{\alpha} d F\left(a_{i}\right)+\int_{a^{l}}^{\underline{a}\left(\eta_{\delta}\right)}\left[k\left(a_{i}\right)^{\alpha}-t\left(a_{i}\right)\right] d F\left(a_{i}\right)
\end{aligned}
$$




$$
-\int_{a^{l}}^{\underline{a}\left(\eta_{\delta}\right)}\left[k\left(a_{i}\right)^{\alpha}-t\left(a_{i}\right)\right] d F\left(a_{i}\right)
$$

and, since $k\left(a_{i}\right)^{\alpha}-t_{i}\left(a_{i}\right)=a_{i}^{\alpha}$ for all $a_{i}>\underline{a}(\eta)$,

$$
\begin{aligned}
& =\int_{a^{l}}^{a^{h}}\left[k\left(a_{i}\right)^{\alpha}-t\left(a_{i}\right)\right] d F\left(a_{i}\right)+\int_{a^{l}}^{\underline{a}\left(\eta_{\delta}\right)}\left[\hat{k}\left(a_{i}+\delta\left(a_{i}-a^{*}\right)\right)^{\alpha}-\eta_{\delta}\right] d F\left(a_{i}\right)-\int_{a^{l}}^{\underline{a}\left(\eta_{\delta}\right)}\left[k\left(a_{i}\right)^{\alpha}-t\left(a_{i}\right)\right] d F\left(a_{i}\right) \\
& =\int_{a^{l}}^{a^{h}}\left[k\left(a_{i}\right)^{\alpha}-t\left(a_{i}\right)\right] d F\left(a_{i}\right)+\int_{a^{l}}^{\underline{a}\left(\eta_{\delta}\right)}\left[\hat{k}\left(a_{i}+\delta\left(a_{i}-a^{*}\right)\right)^{\alpha}-\eta_{\delta}\right] d F\left(a_{i}\right)-\int_{a^{l}}^{\underline{a}(\eta)}\left[k\left(a_{i}\right)^{\alpha}-t\left(a_{i}\right)\right] d F\left(a_{i}\right) \\
& -\int_{\underline{a}(\eta)}^{\underline{a}\left(\eta_{\delta}\right)}\left[k\left(a_{i}\right)^{\alpha}-t\left(a_{i}\right)\right] d F\left(a_{i}\right) \\
& =\int_{a^{l}}^{a^{h}}\left[k\left(a_{i}\right)^{\alpha}-t\left(a_{i}\right)\right] d F\left(a_{i}\right)+\int_{a^{l}}^{\underline{a}\left(\eta_{\delta}\right)}\left[\hat{k}\left(a_{i}+\delta\left(a_{i}-a^{*}\right)\right)^{\alpha}-\eta_{\delta}\right] d F\left(a_{i}\right)-\int_{a^{l}}^{\underline{a}(\eta)}\left[k\left(a_{i}\right)^{\alpha}-\eta\right] d F\left(a_{i}\right) \\
& -\int_{\underline{a}(\eta)}^{\underline{a}\left(\eta_{\delta}\right)} a_{i}^{\alpha} d F\left(a_{i}\right) \\
& =\int_{a^{l}}^{a^{h}}\left[k\left(a_{i}\right)^{\alpha}-t\left(a_{i}\right)\right] d F\left(a_{i}\right)+\int_{a^{l}}^{\underline{a}(\eta)}\left[\hat{k}\left(a_{i}+\delta\left(a_{i}-a^{*}\right)\right)^{\alpha}-\eta_{\delta}-k\left(a_{i}\right)^{\alpha}+\eta\right] d F\left(a_{i}\right) \\
& +\int_{\underline{a}(\eta)}^{\underline{a}\left(\eta_{\delta}\right)}\left[\hat{k}\left(a_{i}+\delta\left(a_{i}-a^{*}\right)\right)^{\alpha}-\eta_{\delta}-a_{i}^{\alpha}\right] d F\left(a_{i}\right)
\end{aligned}
$$

and, since $\delta \in \mathcal{O}, \underline{a}\left(\eta_{\delta}\right) \geq \underline{a}(\eta)$ and for all $a \in\left[a^{l}, \underline{a}(\eta)\right], \hat{k}\left(a_{i}+\delta\left(a_{i}-a^{*}\right)\right)^{\alpha}=\underline{a}\left(\eta_{\delta}\right)^{\alpha}+\eta_{\delta}$ while $k\left(a_{i}\right)^{\alpha}=\underline{a}(\eta)^{\alpha}+\eta$,

$$
\begin{aligned}
& =\int_{a^{l}}^{a^{h}}\left[k\left(a_{i}\right)^{\alpha}-t\left(a_{i}\right)\right] d F\left(a_{i}\right)+\int_{a^{l}}^{\underline{a}(\eta)}\left[\underline{a}\left(\eta_{\delta}\right)^{\alpha}-\underline{a}(\eta)^{\alpha}\right] d F\left(a_{i}\right)+\int_{\underline{a}(\eta)}^{\underline{a}\left(\eta_{\delta}\right)}\left[\underline{a}\left(\eta_{\delta}\right)^{\alpha}-a_{i}^{\alpha}\right] d F\left(a_{i}\right) \\
& \geq \int_{a^{l}}^{a^{h}}\left[k\left(a_{i}\right)^{\alpha}-t\left(a_{i}\right)\right] d F\left(a_{i}\right) \text { which competes the proof. }
\end{aligned}
$$




\section{References}

Acemoglu, D., Golosov, M. and Tsyvinski, A. (2007), "Markets vs. Government", mimeo, MIT.

Acemoglu, D. and Johnson, S. (2005), "Unbundling Institutions", Journal of Political Economy, 113, 949995.

Acemoglu, D., Johnson, S., and Robinson, J.A. (2005), "Institutions as the Fundamental Cause of Long-Run Growth" in: Handbook of Economic Growth, Aghion P. and Durlauf, S. (eds.), North Holland.

Acemoglu, D. and Robinson, J.A. (2007), "Persistence of Elites, Power and Institutions", American Economic Review, forthcoming.

Aghion, P. (1998), "Inequality and Economic Growth", in: Growth, Inequality and Globalization, Cambridge University Press.

Aghion, P. and Bolton, P. (1997), "A Theory of Trickle-Down Growth and Development", Review of Economic Studies, 64, 151-172.

Aghion, P., Caroli, E., and Garcia-Penalosa, C. (1999), "Inequality and Economic Growth: The Perspective of the New Growth Theories", Journal of Economic Literature 37, 161560 .

Andreoni, J. (1989) "Giving with Impure Altruism: Applications to Charity and Ricardian Equivalence", Journal of Political Economy, 97, 1447-1458.

Banerjee, A.V. and Duflo, E. (2003), "Inequality and Growth: What can the Data say?", mimeo, MIT.

Banerjee, A.V. and A.F. Newman (1993), "Occupational Choice and the Process of Development", Journal of Political Economy, 101, 274-298.

Benabou, R. (1996), "Inequality and Growth", Macroeconomics Annual, 11, 11-74.

Bernhardt, D. and Lloyd-Ellis, H. (2000), "Enterprise, Inequality and Economic Development" Review of Economic Studies, 67, 147-168.

Cesari, L. (1983), Optimization: Theory and Applications, Springer-Verlag, New York.

Easterly, D. (2006), "Inequality does Cause Underdevelopment: Insights from a new Instrument", Journal of Development Economics, forthcoming. 
Engerman, S.L. and Sokoloff, K.L. (2002), "Factor Endowments, Inequality, and Paths of Development among New-World Economies," NBER Working Paper \#9259.

Galor, O. and Moav, O. (2006), "Das Human Kapital," Review of Economics Studies, 73, 85-117.

Glaeser, E., La Porta, R., Lopez-de-Silanes, F., and Schleifer, A. (2004) "Do Institutions Cause Growth?", Journal of Economic Growth, 9, 271-303.

Kocherlakota, N. (2005), "Zero Expected Wealth Taxes: A Mirrlees Approach to Dynamic Optimal Taxation", Econometrica, 73, 1587-1621.

Koeppl, T. (2007), "Optimal Dynamic Risk Sharing when Enforcement is a Decision Variable", Journal of Economic Theory, 134, 34-60.

Persson, T. and Tabellini, G. (1994), "Is Inequality Harmful for Growth?" The American Economic Review, 84, 600-621.

Rajan, R., (2007), "The Persistence of Underdevelopment: Constitutiences and Competitive Rent Preservation", mimeo, University of Chicago.

Rajan, R., and Zingales L. (2003), Saving Capitalism from the Capitalists: Unleashing the Power of Financial Markets to Create Wealth and Spread Opportunity, Princeton University Press.

Rogerson, W.P. (1985), "Repeated Moral Hazard", Econometrica, 53, 69-76.

Sappington, D. (1983), "Limited Liability Contracts between Principal and Agent", Journal of Economic Theory, 29, 1-21. 